\title{
Magnetic and $\mathrm{pH}$ dual-responsive mesoporous silica nanocomposites for effective and low-toxic photodynamic therapy
}

This article was published in the following Dove Press journal:

International Journal of Nanomedicine

10 April 2017

Number of times this article has been viewed

\author{
Jieqiong Zhan ${ }^{1,2, *}$ \\ Zhiqiang $\mathrm{Ma}^{2}$,* \\ Dan Wang ${ }^{3}$ \\ Xinfang $\mathrm{Li}^{2}$ \\ Xiangui $\mathrm{Li}^{2}$ \\ Lijing Le ${ }^{2}$ \\ Anfeng Kang ${ }^{2}$ \\ Pengwei $\mathrm{Hu}^{\prime}$ \\ Lan She ${ }^{2}$ \\ Feng Yang ${ }^{1,2}$ \\ 'Department of Pharmacy, Hebei \\ North University, Zhangjiakou, Hebei, \\ ${ }^{2}$ Department of Inorganic Chemistry, \\ School of Pharmacy, ${ }^{3}$ Department of \\ Obstetrics and Gynecology, Shanghai \\ Changzheng Hospital, Second Military \\ Medical University, Shanghai, People's \\ Republic of China
}

*These authors contributed equally to this work
Correspondence: Feng Yang Department of Inorganic Chemistry, School of Pharmacy, Second Military Medical University, 325 Guohe

Road, Shanghai 200433, People's

Republic of China

Tel +86 2I 8I87 I2I8

Email yangfeng I008@I26.com
Abstract: Nonspecific targeting, large doses and phototoxicity severely hamper the clinical effect of photodynamic therapy (PDT). In this work, superparamagnetic $\mathrm{Fe}_{3} \mathrm{O}_{4}$ mesoporous silica nanoparticles grafted by $\mathrm{pH}$-responsive block polymer polyethylene glycol- $b$-poly(aspartic acid) (PEG- $b$-PAsp) were fabricated to load the model photosensitizer rose bengal (RB) in the aim of enhancing the efficiency of PDT. Compared to free RB, the nanocomposites (polyethylene glycol- $b$-polyaspartate-modified rose bengal-loaded magnetic mesoporous silica [RB-MMSNs]) could greatly enhance the cellular uptake due to their effective endocytosis by mouse melanoma B16 cell and exhibited higher induced apoptosis although with little dark toxicity. RB-MMSNs had little dark toxicity and even much could be facilitated by magnetic field in vitro. RB-MMSNs demonstrated 10 times induced apoptosis efficiency than that of free $\mathrm{RB}$ at the same RB concentration, both by cell counting kit-8 (CCK-8) result and apoptosis detection. Furthermore, RB-MMSNs-mediated PDT in vivo on tumor-bearing mice showed steady physical targeting of RB-MMSNs to the tumor site; tumor volumes were significantly reduced in the magnetic field with green light irradiation. More importantly, the survival time of tumor-bearing mice treated with RB-MMSNs was much prolonged. Henceforth, polyethylene glycol-b-polyaspartate-modified magnetic mesoporous silica (MMSNs) probably have great potential in clinical cancer photodynamic treatment because of their effective and low-toxic performance as photosensitizers' vesicles.

Keywords: magnetic mesoporous silica, rose bengal, polymer polyethylene glycol- $b$ poly(aspartic acid), magnetic targeting, $\mathrm{pH}$ responsive, photodynamic therapy

\section{Introduction}

Photodynamic therapy (PDT) that emerged in the 1970s has a wide range of application in clinics, including treating melanoma, breast cancer, superficial tumors, psoriasis and atherosclerosis; also it shows certain effects in anti-infection of viruses such as human papilloma virus (HPV). ${ }^{1-4}$ In recent years, PDT has achieved rapid progress both in fundamental research ${ }^{5-8}$ and clinic practice, ${ }^{9-11}$ which makes it become the fourth minimal invasive therapy for cancer treatment following surgery, radiotherapy and chemotherapy. ${ }^{12}$ PDT is based on the principle that light-activated photosensitizer can produce lethal cytotoxic active singlet oxygen $\left({ }^{1} \mathrm{O}_{2}\right)$ and other reactive oxygen species (ROS) to damage tumors and their surrounding vasculature when the tumor tissues uptaking the photosensitizer are irradiated with a specific wavelength light in the presence of tissue oxygen. Moreover, PDT has some advantages such as minimal biotoxicity to peripheral normal tissues and nonexistent drug resistance compared with chemotherapy. However, most photosensitizers such as nonspecific 
targeting drugs are confronted with problems such as too large dose because of well distribution inside the whole body and potential severe phototoxicity all over the body in clinics $;{ }^{13,14}$ hence, specific targeting and controlled release of photosensitizers are urgent demands in clinics. Although researches on the delivery system of photosensitizers have flourished in recent years, low enriching efficiency of photosensitizers still severely hamper the therapeutic effect of PDT. ${ }^{15,16}$ In these researches, photosensitizer dose is always too large to guarantee the therapeutic effect in clinics, which increases potential phototoxicity to the normal tissues. Specificity and controllability of some photpsensitizers at the tumor site have been performed to improve retention; herein, we fabricated a novel magnetic mesoporous silica nanoparticle (MMSN) to deliver photosensitizer to the target site using the magnetic targeting technology. ${ }^{17-19}$ MMSN can be utilized in magnetic resonance imaging (MRI) and magnetic targeting to trace and guide drug delivery in vivo; meanwhile, combined with the advantages of mesoporous materials, including large pore size, large specific surface area, stable structure and modifiable inner surface, MMSN exert good drug-loading capacity and biocompatibility as reported. ${ }^{20,21}$

In order to reduce the drug leakage and toxicity in the delivering process, $\mathrm{pH}$-responsive functional polymer is designed to be grafted onto the surface of magnetic mesoporous silica sphere. ${ }^{22,23}$ Henceforth, the composites were endowed with both magnetic targeting and $\mathrm{pH}$ responsibility, which made photosensitizer rapidly and efficiently released in targeting tissues. Additionally, phototoxicity was greatly decreased due to the reduction in the dose of photosensitizers to the minimal effective dose.

As illustrated in Figure 1, a pH-responsive and magnetic targeting photodynamic therapeutic composite $\mathrm{Fe}_{3} \mathrm{O}_{4} @$ nSiO $@ \mathrm{mSiO}_{2} @ \mathrm{RB} @$ PEG- $b$-PAsp (polyethylene glycol$b$-polyaspartate-modified rose bengal-loaded magnetic mesoporous silica [RB-MMSNs]) were fabricated to deliver the photosensitizer to tumor sites. We utilized $\mathrm{Fe}_{3} \mathrm{O}_{4}$ as the magnetic core for magnetic targeting, which could also be used as the contrast agent to trace the drug and the location of tumor tissues, ${ }^{24}$ we fabricated the solid silica layer $\mathrm{nSiO}_{2}$ to prevent the $\mathrm{Fe}_{3} \mathrm{O}_{4}$ core from oxidation. Moreover, mesoporous silica layer $\mathrm{mSiO}_{2}$ was utilized to load the photosensitizer and the medium to be modified with the $\mathrm{pH}$-responsive polymer. The polymer polyethylene glycol- $b$-poly(aspartic acid) (PEG- $b$-PAsp) is a novel $\mathrm{pH}$-responsive polymer in recent years, which demonstrates excellent $\mathrm{pH}$ responsiveness and biocompatibility. ${ }^{25}$ Furthermore, nontoxic and stable rose bengal $(\mathrm{RB})$ with a high yield of ${ }^{1} \mathrm{O}_{2}, \sim 0.76$, is taken as the modal photosensitizer because of its good affinity to mesoporous silica. ${ }^{26}$ In our study, efficiency and precision of PDT are greatly enhanced with polyethylene glycol- $b$-polyaspartate-modified magnetic mesoporous silica (MMSNs) as the carrier of RB; contrarily, risk of RB phototoxicity is significantly decreased because of its much lower effective dose.

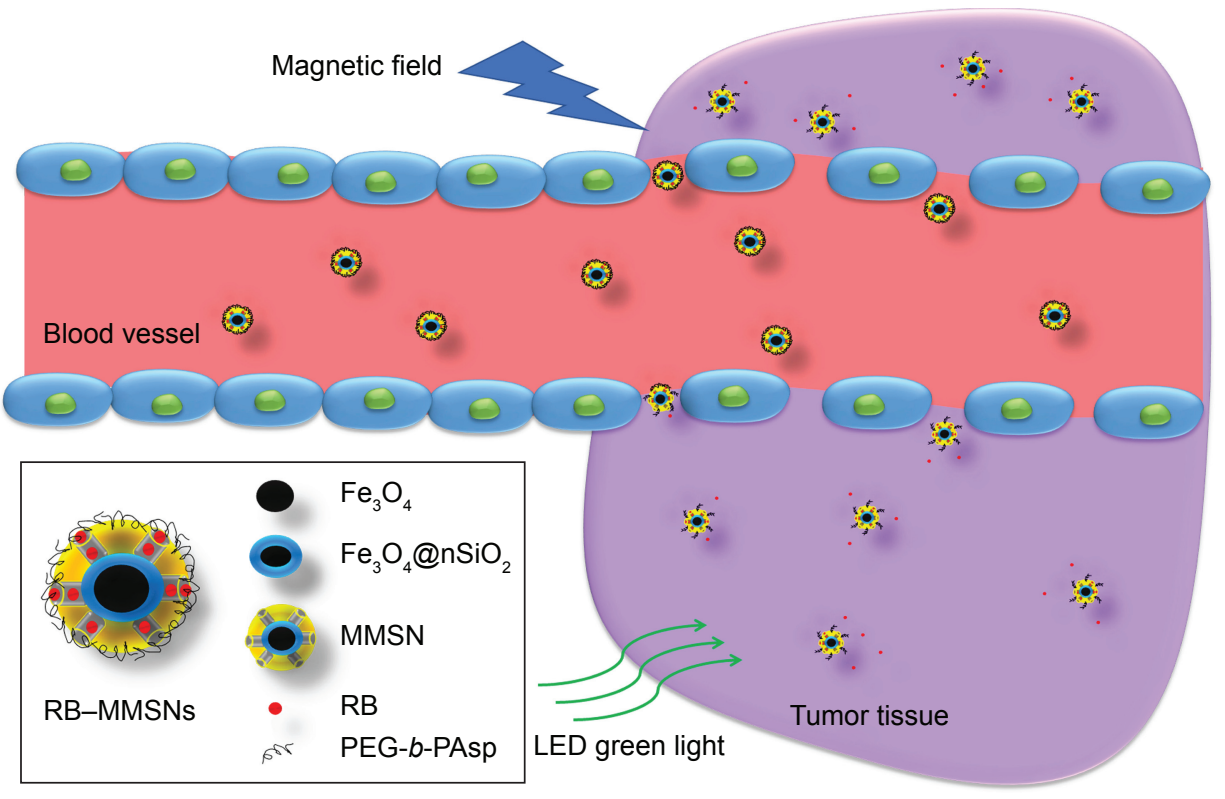

Figure I Illustration of MMSN-mediated treatment in a magnetic field.

Note: RB was loaded into the mesoporous silica pores and surrounded by PEG-b-PAsp in blood vessels, when they were released in tumor sites.

Abbreviations: MMSN, magnetic mesoporous silica nanoparticle; RB, rose bengal; PEG-b-PAsp, polyethylene glycol-b-poly(aspartic acid); RB-MMSNs, polyethylene glycolb-polyaspartate-modified rose bengal-loaded magnetic mesoporous silica. 


\section{Materials and methods Materials}

Ferric chloride hexahydrate $\left(\mathrm{FeCl}_{3} \cdot 6 \mathrm{H}_{2} \mathrm{O}\right)$, sodium acetate $\left(\mathrm{CH}_{3} \mathrm{COONa}\right.$ or $\left.\mathrm{NaOAc}\right)$, dihydrated sodium citrate $\left(\mathrm{Na}_{3} \mathrm{Cit} \cdot 2 \mathrm{H}_{2} \mathrm{O}\right)$, ethylene glycol (EG), tetraethyl orthosilicate (TEOS), cetyltrimethylammonium bromide (CTAB) and ammonium hydroxide $\left(\mathrm{NH}_{3} \cdot \mathrm{H}_{2} \mathrm{O}\right)$ were purchased from Chinese Medicine Group Chemical Reagent Co., Ltd. (Shanghai, People's Republic of China). (3-Aminopropyl)triethoxysilane (APTES), RB, 1-ethyl-3-(3-dimethylaminopropyl) carbodiimide hydrochloride (EDC $\cdot \mathrm{HCl}$ ) and $N$-hydroxysulfosuccinimide (NHS) were purchased from Aladdin (Shanghai, People's Republic of China).

\section{Fabrication of MMSNs}

$\mathrm{Fe}_{3} \mathrm{O}_{4}$ nanoparticles were synthesized by solvothermal reaction (Supplementary materials) as reported in our previous research. ${ }^{27}$ Solid silica was coated onto the surface of $\mathrm{Fe}_{3} \mathrm{O}_{4}$ by the Stöber sol-gel process, ${ }^{28}$ and the $\mathrm{Fe}_{3} \mathrm{O}_{4} @ \mathrm{nSiO}_{2}$ nanoparticles were entrapped with mesoporous silica using the soft template method. ${ }^{29}$ Particularly, $\mathrm{Fe}_{3} \mathrm{O}_{4}(10 \mathrm{mg} / \mathrm{mL})$ nanoparticles were dripped into a preprepared solution $\left(10 \mathrm{~mL} \cdot \mathrm{H}_{2} \mathrm{O}\right.$, $35 \mathrm{~mL} \mathrm{C}_{2} \mathrm{H}_{5} \mathrm{OH}$ ). After stirring for $15 \mathrm{~min}$ at $400 \mathrm{rpm}, 1 \mathrm{~mL}$ $\mathrm{NH}_{3} \cdot \mathrm{H}_{2} \mathrm{O}$ was added dropwise into the system. Keeping stirring for $15 \mathrm{~min}, 70 \mu \mathrm{L}$ TEOS dispersed in $3 \mathrm{~mL}$ anhydrous ethanol was dripped into the system. After vigorously stirring for $5 \mathrm{~h}$, the nanoparticles were separated by neodymium, iron and boron (NIB; size $3 \times 1.5 \times 1 \mathrm{~cm}$, purchased from Dongguan Fuqiang Magnetic Industry Co., Ltd. [Dongguan, People's Republic of China]; the maximum magnetic energy product was $285 \mathrm{~kJ} / \mathrm{m}^{3}$ ) magnet, and the nanoparticles were alternately washed by deionized water and anhydrous ethanol for three times. The nanoparticles were then dried up in vacuum. In the second step, 10 mg Fe $\mathrm{O}_{4} @ \mathrm{nSiO}_{2}$ nanoparticles were dispersed in $5 \mathrm{~mL}$ of $\mathrm{H}_{2} \mathrm{O}$ ultrasonically. $\mathrm{CTAB}$ solution ( $15 \mathrm{mg} \mathrm{CTAB}$ dissolved in $5 \mathrm{~mL} \mathrm{H}_{2} \mathrm{O}$ and $3 \mathrm{~mL} \mathrm{C}_{2} \mathrm{H}_{5} \mathrm{OH}$ ) was stirred for 5 min until the system was homogenous. Afterward, $55 \mu \mathrm{L}$ ammonia solution was dripped into the system, and then $80 \mathrm{~mL}$ TEOS (dispersed in $3 \mathrm{~mL}$ anhydrous ethanol) was dripped. After stirring for $4 \mathrm{~h}$, the particles were separated by the NIB magnet followed by alternate washing with deionized water and anhydrous ethanol for three times. Then, the nanoparticles were refluxed in anhydrous ethanol at $92^{\circ} \mathrm{C}$ for $72 \mathrm{~h}$. Finally, MMSN were dried up in vacuum and obtained as a dark gray powder.

PEG- $b$-PAsp was also synthesized (Supplementary materials) during the fabrication process of MMSNs according to our previous research. ${ }^{22}$ Amination of MMSN was proceeded first; ${ }^{30} 50 \mathrm{mg}$ MMSN were then added into a solution of APTES ( $30 \mu \mathrm{L}$ APTES dissolved in $30 \mathrm{~mL}$ anhydrous ethanol). After stirring at room temperature for $48 \mathrm{~h}$, the product was then separated by the NIB magnet, washed alternatively with deionized water and anhydrous ethanol for three times and dried in vacuum, the dried MMSN-NH were obtained as a dark gray powder. Polymerization was proceeded afterward. MMSN- $\mathrm{NH}_{2}(20 \mathrm{mg})$ were dispersed in $10 \mathrm{~mL}$ deionized water ultrasonically, and then, EDC $(16 \mathrm{mg})$ and NHS (4 mg) were respectively added into the dispersed system at a stirring speed of $300 \mathrm{rpm}$ for $5 \mathrm{~min}$. Then PEG$b$-PAsp $(50 \mathrm{mg}$ ) was added into the mixture. After stirring for $4 \mathrm{~h}$, the product was washed by deionized water for three times; MMSNs were obtained after a freeze-dried process.

\section{Preparation of polyethylene glycol-b- polyaspartate-modified rose bengal- loaded magnetic mesoporous silica (RB-MMSNs)}

As illustrated in Figure 2, RB was per-loaded in MMSN before grafting PEG- $b$-PAsp onto the mesoporous silica shell. RB was mixed with MMSN and kept stirring in dark environment for $24 \mathrm{~h}$, and then, RB-loaded MMSN were separated by the NIB magnet and washed with deionized water to remove free RB molecules. At last, RB-MMSNs were obtained by the freeze-drying procedure.

\section{Characterization of the materials}

The microstructure of composites was observed using a transmission electron microscope (TEM; TecnaiG ${ }^{2}$ F20 S-Twin; FEI, Hillsboro, OR, USA) at $200 \mathrm{kV}$, and the samples were dispersed in ethanol and dropped onto a holey carbon film supported on a $\mathrm{Cu}$ grid. Nitrogen isotherm adsorption/ desorption was measured at $-196^{\circ} \mathrm{C}$ with a TriStar 3000 analyzer (Micromeritics, Atlanta, GA, USA). The mean size and crystal lattice properties of nanoparticles were analyzed by X-ray powder diffraction (XRD; X'pert PRO; PANalytical B.V., Almelo, the Netherlands) with a scanning range from $20^{\circ}$ to $80^{\circ}$. Magnetic characterization was carried out with a vibrating sample magnetometer (VSM) on a model 6000 physical property measurement system (Quantum, San Jose, CA, USA) at $300 \mathrm{~K}$. Photosensitizer content, $\mathrm{pH}$ responsiveness and amount of ${ }^{1} \mathrm{O}_{2}$ of RB-MMSNs were characterized by ultraviolet-visible (UV/VIS) spectra (Lambda 25; PerkinElmer, Waltham, MA, USA). Additionally, process of fabrication was validated in the range of $400-4,000 \mathrm{~cm}^{-1}$ by the Fourier transform infrared spectroscopy (FTIR) analysis (Nexus Model 470; GMI, Ramsey, MN, USA). 

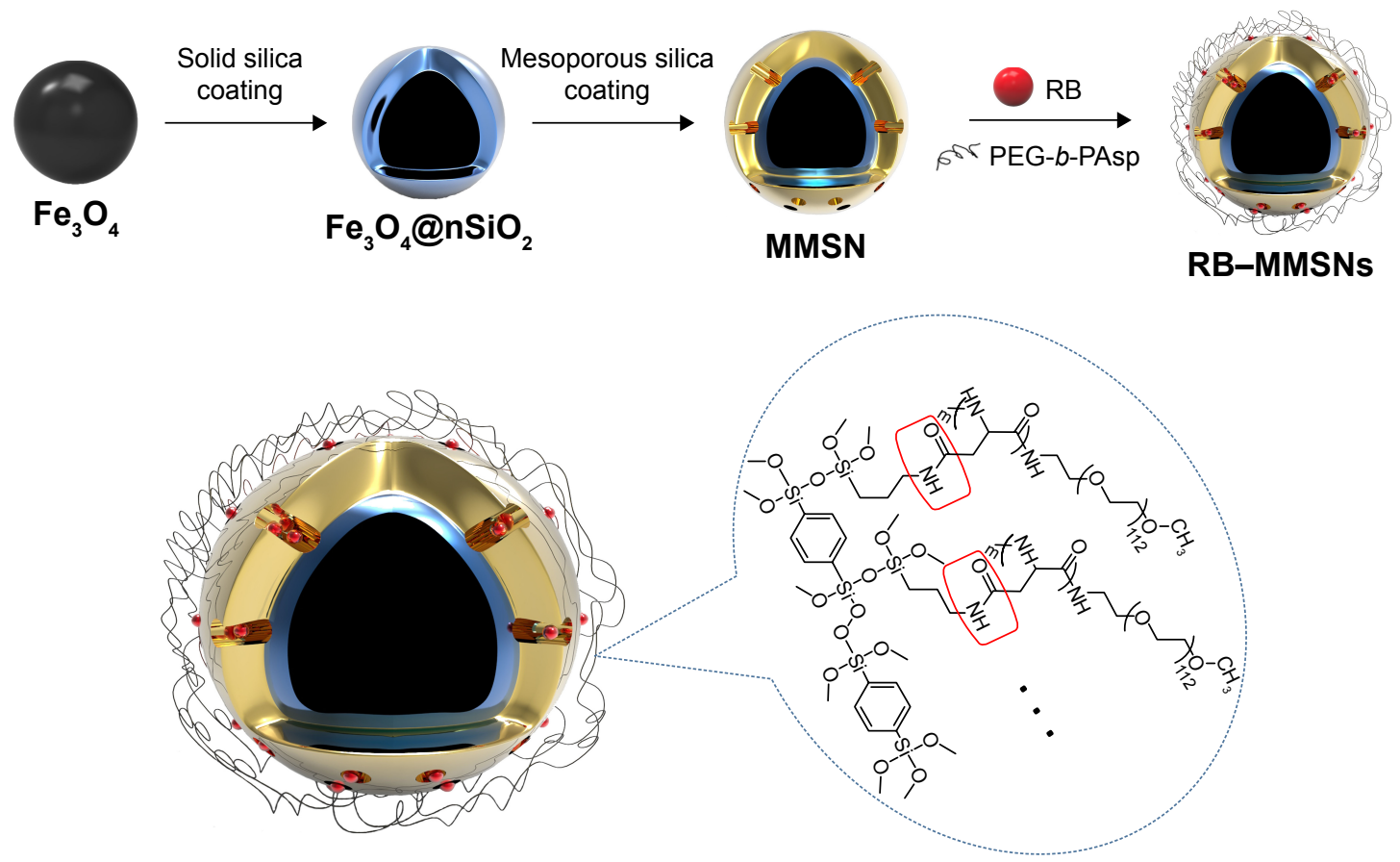

Figure 2 Schematic illustration for the synthesis of core-shell RB-MMSNs.

Abbreviations: RB-MMSNs, polyethylene glycol-b-polyaspartate-modified rose bengal-loaded magnetic mesoporous silica; MMSN, magnetic mesoporous silica nanoparticle; $\mathrm{RB}$, rose bengal; PEG-b-PAsp, polyethylene glycol-b-poly(aspartic acid).

\section{Determination of RB loading efficiency}

A total of $5 \mathrm{mg}$ of above-prepared RB-MMSNs were ultrasonically dispersed in phosphate-buffered saline (PBS; $\mathrm{pH}$ 5.2), stirred for $24 \mathrm{~h}$ in a dark room and separated by the NIB magnet. The absorbance of the supernatant fluid at $559 \mathrm{~nm}$ was measured by UV/VIS, and then, the RB-loaded rate was calculated as follows: RB-loaded rate $(\%)=($ mass of RB in RB-MMSNs/total mass of the RB-MMSNs).

\section{Cellular uptake and magnetic targeting in vitro}

B16 mouse melanoma cells were presented by the National Key Laboratory of Medical Immunology (Shanghai, People's Republic of China) and incubated in a Roswell Park Memorial Institute medium (RPMI)-1640 culture medium (10\% fetal bovine serum, $1 \%$ penicillin-streptomycin) at $37^{\circ} \mathrm{C}$ with $5 \% \mathrm{CO}_{2}$. A total of $1 \times 10^{5} \mathrm{~B} 16$ cells were seeded into six-well plates. After incubating for $12 \mathrm{~h}$, the culture medium, RB-MMSNs, and free RB were respectively added into the plates. After $4 \mathrm{~h}, \mathrm{~B} 16$ cells in each well of plates were washed by PBS for three times and fixed by $1 \mathrm{~mL} 1 \mu \mathrm{g} / \mathrm{mL}^{-1}$ paraformaldehyde for $20 \mathrm{~min}$. Then, the cells were stained by 4',6-diamidinio-2-phenylindole (DAPI) for $20 \mathrm{~min}$ before inspecting under a fluorescence microscope (IX71; Olympus Corporation, Tokyo, Japan). Meanwhile, cellular uptake was observed under a biological TEM (H-7650; Hitachi, Tokyo,
Japan). B16 cells were incubated in a culture dish with a diameter of $10 \mathrm{~cm}$ until $80 \%-90 \%$ surface of the culture dish was covered by B 16 cells. After the culture medium was discarded, MMSNs ( $50 \mu \mathrm{g} / \mathrm{mL}, 6 \mathrm{~mL}$ ) were added into the culture dish. Kept incubating for $4 \mathrm{~h}$, the cells were digested and collected and then washed by PBS. After fixing the cells with the prepared cellular fixture (2.5\% glutaraldehyde), samples were kept in $4^{\circ} \mathrm{C}$ for 4-6 $\mathrm{h}$ before observation under the biological TEM.

For the study of magnetic targeting in vitro, B16 cells were seeded onto four microscope slides $\left(1 \times 10^{5}\right.$ on each slide) incubated in two culture dishes separately. MMSNs $\left(10 \mu \mathrm{g} / \mathrm{mL}^{-1}\right)$ and RB-MMSNs $\left(10 \mu \mathrm{g} / \mathrm{mL}^{-1}\right)$ were added to each slide and then NIB magnet (size $1.6 \times 0.8 \mathrm{~cm}$, purchased from Dongguan Fuqiang Magnetic Industry Co., Ltd.; the maximum magnetic energy product was $285 \mathrm{~kJ} / \mathrm{m}^{3}$ ) was set under one slide of each culture dish for $2 \mathrm{~h}$ (sway the dishes every $15 \mathrm{~min}$ ). After washing the cells by PBS for three times, the fluorescent density was detected with flow cytometry (BD FACSCalibur; BD Biosciences, Franklin Lakes, NJ, USA).

\section{Cytotoxicity and detection of cellular ROS}

Cell counting kit-8 (CCK-8) was used to analyze the cytotoxicity of MMSNs to the normal mouse fibroblast cells (L929) and two other kinds of cancer cells, human cervical 
cancer cells (Hela, derived from a cervical carcinoma) and B16 cells. All the cells were presented by the National Key Laboratory of Medical Immunology (Shanghai, People's Republic of China). All cellular experiments were approved by the institutional review board of Second Military Medical University and performed in accordance with the Guiding Principles for the Management of Cellular Laboratory, Second Military Medical University. These three kinds of cells were seeded onto six 96-well plates at a density of $1 \times 10^{4} /$ well for $12 \mathrm{~h}$. MMSNs with concentrations ranging from 4 to $200 \mu \mathrm{g} / \mathrm{mL}$ were added and incubated for $24 \mathrm{~h}$ or $48 \mathrm{~h}$. Then, CCK- 8 method was used to measure the cellular viability by a microplate reader (ELx800; BioTek, Winooski, VT, USA) at a wavelength of $450 \mathrm{~nm}$.

CCK-8 method was also utilized to observe the therapeutical effect of RB-MMSNs. A total of $1 \times 10^{4} \mathrm{~B} 16$ cells were seeded into each well of two 96-well plates, and then, RB-MMSNs and free RB at the concentration of $1.56-50 \mu \mathrm{g} / \mathrm{mL}$ were separately added into the culture medium. After incubating in dark environment for $12 \mathrm{~h}$, one of the 96-well plate was irradiated with $535 \mathrm{~nm}$ green light (AT063-G; Hongying Technology Co. Ltd, Shenzhen, People's Republic of China) for $3 \mathrm{~min}$, and then, two 96-well plates were incubated for another $24 \mathrm{~h}$; CCK- 8 method was used to measure the cellular viability.

Cellular apoptosis was adopted to assess the therapeutical effect of the RB-MMSNs. A total of $2 \times 10^{5}$ B16 cells were seeded into six-well plates for $12 \mathrm{~h}$. Cells were washed by PBS, and RB-MMSNs $(1.56 \mu \mathrm{g} / \mathrm{mL}, 3.125 \mu \mathrm{g} / \mathrm{mL}$ and $6.25 \mu \mathrm{g} / \mathrm{mL})$ and free $\mathrm{RB}(3.125 \mu \mathrm{g} / \mathrm{mL})$ were added. After incubation for $12 \mathrm{~h}$, one plate was irradiated by $535 \mathrm{~nm}$ green light for $3 \mathrm{~min}$; the cells were incubated for another $12 \mathrm{~h}$. Then, cells were collected, digested and stained with FITCAnnexin V/PI Kit (Shanghai Biotend Technology Co. Ltd., Shanghai, People's Republic of China).

A total of $5 \times 10^{4}$ B16 cells were seeded into a 96-well plate. After incubating for $12 \mathrm{~h}$, cells were washed by PBS and different concentrations of MMSNs (2.81-90 $\mu \mathrm{g} / \mathrm{mL})$, RB-MMSNs $(1.56-50 \mu \mathrm{g} / \mathrm{mL})$ and free RB were added into the plate, and then, the cells were incubated in dark environment for $12 \mathrm{~h}$ and washed with PBS. Then, $100 \mu \mathrm{L}$ dichloro-dihydro-fluorescein diacetate (DCFH-DA, $100 \mathrm{M}$ ) was added into each well and absorbance was determined by a microplate reader (Lambda $25 ; \lambda_{\mathrm{ex}}=488 \mathrm{~nm}, \lambda_{\mathrm{em}}=525 \mathrm{~nm}$ ) after irradiating the plate with $535 \mathrm{~nm}$ green light.

\section{Magnetic targeting and PDT in vivo}

C57BL/6J (18-20 g) male mice were purchased from Shrek Animal Co. Ltd. (Shanghai, People's Republic of China). All animal experiments were performed in compliance with the Guiding Principles for the Care and Use of Laboratory Animals, Second Military Medical University, People's Republic of China. Protocols were approved by the Institutional Animal Care and Use Committee of the Second Military Medical University. Mice models were prepared by injecting a total of $1 \times 10^{5}$ B16 cells in a $100 \mu \mathrm{L}$ culture medium into right hindlegs subcutaneously. Till the tumor volume was $\sim 80 \mathrm{~mm}^{3}$, mice were randomly divided into two groups (mice within the magnet group and without the magnet group) for MRI in vivo; RB-MMSNs ( $18 \mathrm{mg} / \mathrm{kg}$ ) were injected into mice intravenously whose tumor sites were bound closely to the NIB magnet. $\mathrm{T}_{2}$-weighted images were obtained at three time points (pro-injection, injection and post-injection for $2 \mathrm{~h}$ with or without the NIB magnet) for every mouse by $3 \mathrm{~T}$ Clinical MRI Scanner (Signa HDxt 3.0T; General Electric Company, Fairfield, CT, USA) equipped with a small animal imaging system; furthermore, all mice were sacrificed to qualitatively analyze distribution of the iron in vivo by staining the main organs and tumor tissues with Prussian blue.

To study MMSNs-mediated therapeutic effect of PDT in vivo, 32 mice were divided into four groups with eight mice in each group. Mice were treated with saline (control), free RB PDT (RB+), RB-MMSNs without NIB magnet (RB-MMSNs+) and RB-MMSNs within NIB magnet $(\mathrm{M}+\mathrm{RB}-\mathrm{MMSNs}+)$. Six days after tumor inoculation, mice of the $\mathrm{RB}+$ group were intravenously injected with $\mathrm{RB}(6.25 \mathrm{mg} \mathrm{RB} / \mathrm{kg})$, while mice in the other groups were injected with RB-MMSNs (6.25 mg RB/kg) except the saline group. NIB magnet was bound to the tumor sites of M+RB-MMSNs+ PDT group for $2 \mathrm{~h}$. Afterward, tumor sites of all mice except the control group were irradiated by $535 \mathrm{~nm}$ green light (Figure S1) at $25 \mathrm{~mW} / \mathrm{cm}^{3}$ for 20 min with a treatment cycle: every 2 days for five times; also, body weight of mice, length and width of tumors and survival periods were recorded every 2 days. Tumor volume was calculated by the following equation: (length of tumor) $\times(\text { width of tumor })^{2} / 2$; furthermore, all the treated mice were sacrificed for apoptosis detection of tumor cells on 15th day after tumor inoculation. The apoptotic cells were detected with terminal deoxynucleotidyl transferase dUTP nick-end labeling (TUNEL) assays with an in situ cell death detection kit.

\section{Results and discussion Preparation and characterization of RB-MMSNs}

Morphology of MMSN was observed under the TEM (Figure 3A): Magnetic core $\mathrm{Fe}_{3} \mathrm{O}_{4}$ emerged favorable sphere morphology $(\sim 140 \mathrm{~nm})$ with good dispersion in hydrophilic 


\section{A}
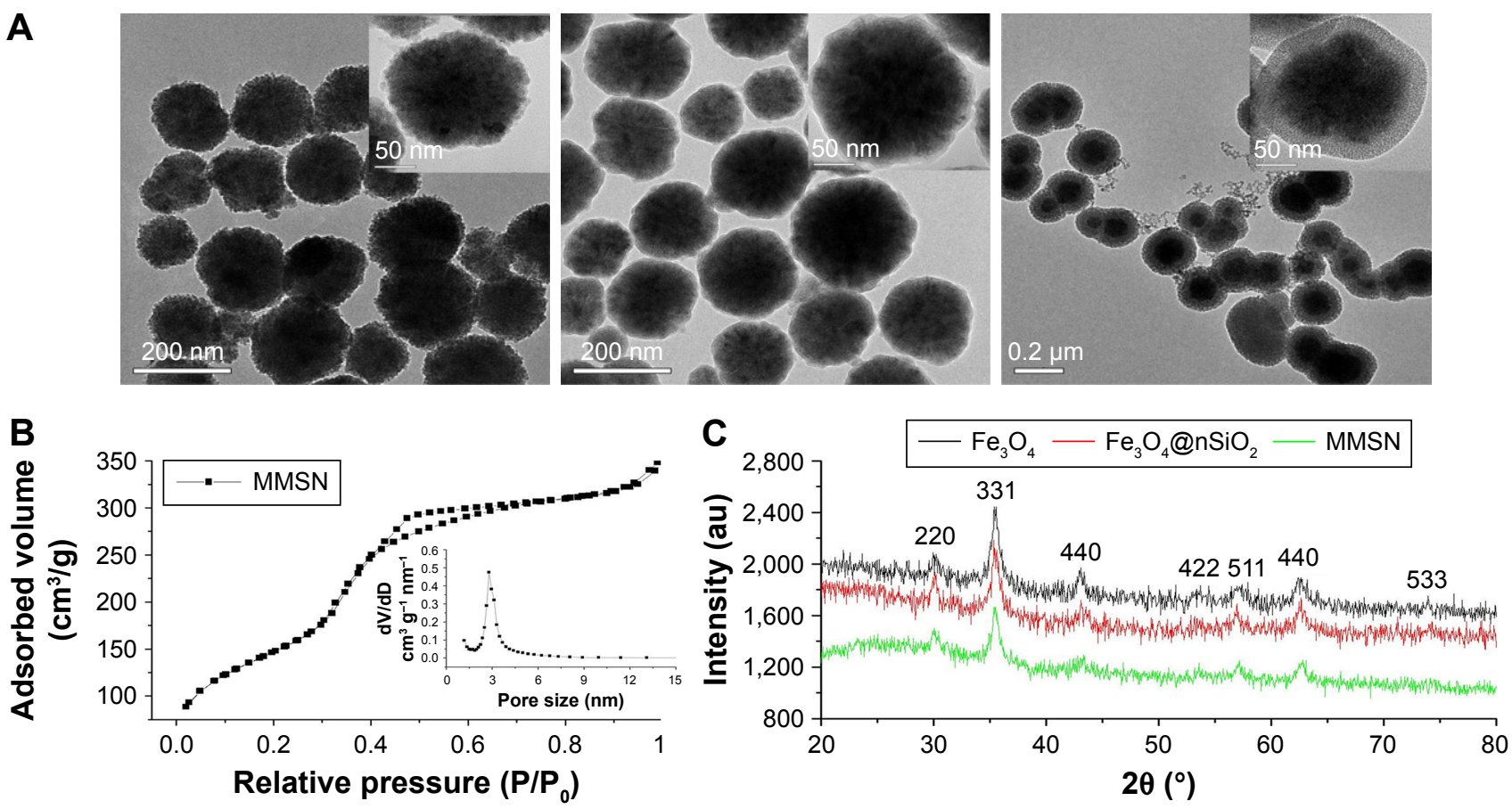

Figure 3 The structural characterization of samples.

Notes: (A) The TEM images of $\mathrm{Fe}_{3} \mathrm{O}_{4}, \mathrm{Fe}_{3} \mathrm{O}_{4} @ \mathrm{nSiO}_{2}$ and MMSN. (B) BET nitrogen absorption/desorption isotherms for MMSN. Inset shows $\mathrm{BJH}$ pore size distributions of MMSN. (C) Wide-angel XRD patterns of $\mathrm{Fe}_{3} \mathrm{O}_{4}, \mathrm{Fe}_{3} \mathrm{O}_{4} @ n \mathrm{niO}_{2}$ and MMSN.

Abbreviations: TEM, transmission electron microscope; MMSN, magnetic mesoporous silica nanoparticle; BET, Brunauer-Emmett-Teller; BJH, Barrett-Joyner-Halenda; $\mathrm{XRD}, \mathrm{X}$-ray diffraction; au, atomic unit.

solvents. The size of MMSN increased to $190 \mathrm{~nm}$ with apparent mesoporous layer. To probe into the details of the mesoporous structure of MMSN, $\mathrm{N}_{2}$ desorption and adsorption tests were taken (Figure 3B). The isothermal curve was similar to the IV-type isothermal curve. Hysteresis loop hinted MMSN with a mesoporous architecture (pore size $=3.12 \mathrm{~nm}$, Brunauer-Emmett-Teller $[\mathrm{BET}]$ surface area $=547.81 \mathrm{~m}^{2} / \mathrm{g}$, pore volume $=0.54 \mathrm{~cm}^{3} / \mathrm{g}$ ). All these properties ensured the loading efficiency of photosensitizer to nanocomposites. The powder X-ray diffraction (XRD) demonstrated the crystalline nature of $\mathrm{Fe}_{3} \mathrm{O}_{4}, \mathrm{Fe}_{3} \mathrm{O}_{4} @ \mathrm{nSiO}_{2}$ and MMSN (Figure 3C), which was compatible with the values of standard $\mathrm{Fe}_{3} \mathrm{O}_{4} \cdot{ }^{31}$

Amphiphilic and $\mathrm{pH}$-sensitive polymer PEG- $b$-PAsp was synthesized by ring-opening reaction through three steps. ${ }^{32}$ Then, to have an increased RB loading efficiency, better biocompatibility and $\mathrm{pH}$-sensitivity for the RB-MMSNs, the polymer was grafted onto the surface of mesoporous silica by amidation reaction. $\mathrm{C}-\mathrm{O}-\mathrm{C}$ and $\mathrm{C}=\mathrm{O}$ peaks belonging to PEG- $b$-PAsp advented in the FTIR spectrum of MMSNs ${ }^{33}$ proved a successful grafting of PEG- $b$-PAsp onto the mesoporous silica surface (Figure 4A).

Then, the magnetic property of $\mathrm{Fe}_{3} \mathrm{O}_{4}, \mathrm{MMSNs}$ and RB-MMSNs were studied. As prepared, such nanomaterials showed superparamagnetic property owing to the absence of hysteresis loops, zero value of the coercivity and remanence by VSM (Figure 4B). The magnetic saturation strength of RB-MMSNs (26.6 emu/g) was decreased compared to that of $\mathrm{Fe}_{3} \mathrm{O}_{4}(60 \mathrm{emu} / \mathrm{g})$. However, after being exposed to an external magnetic field, RB-MMSNs were quickly assembled to the side near the magnet (Figure 4B, inset). Superparamagnetic $\mathrm{Fe}_{3} \mathrm{O}_{4}$ nanoparticles are a good $\mathrm{T}_{2}$ contrast agent, ${ }^{34-36}$ depending on the darkening effect to distinguish the contrast area with normal sites. $\mathrm{T}_{2}$-weighted MRI showed a concentration-dependent darkening effect, and the relaxation rate $\left(R_{2}\right)$ of RB-MMSNs was $\sim 52.51 \mathrm{~S}^{-1} \cdot \mathrm{mM}^{-1}$, closely to $R_{2}\left(58.35 \mathrm{~S}^{-1} \cdot \mathrm{mM}^{-1}\right)$ of $\mathrm{Fe}_{3} \mathrm{O}_{4}$ (Figure $4 \mathrm{C}$ ).

\section{Determination of RB loading efficiency, $\mathrm{pH}$-responsive release in vitro and detection of singlet oxygen}

In Figure 5A, MMSNs showed a much higher RB loading efficiency of $35.74 \% \pm 0.04 \%$ than $\mathrm{Fe}_{3} \mathrm{O}_{4} @ \mathrm{nSiO}_{2}$ and MMSN, which demonstrated that the PEG- $b$-PAsp-modified MMSNs could increase the RB loading capacity.

The $\mathrm{pH}$-responsive release of $\mathrm{RB}$ was determined in PBS in different $\mathrm{pH}$ conditions ( $\mathrm{pH} 5.2,7.4)$ by simulating the normal and acidic tumor microenvironments (Figure 5B). In the condition of $\mathrm{pH} 5.2, \sim 80 \%$ of RB was released at $12 \mathrm{~h}$, while only $50 \%$ of RB was released even over $72 \mathrm{~h}$ in the 
A

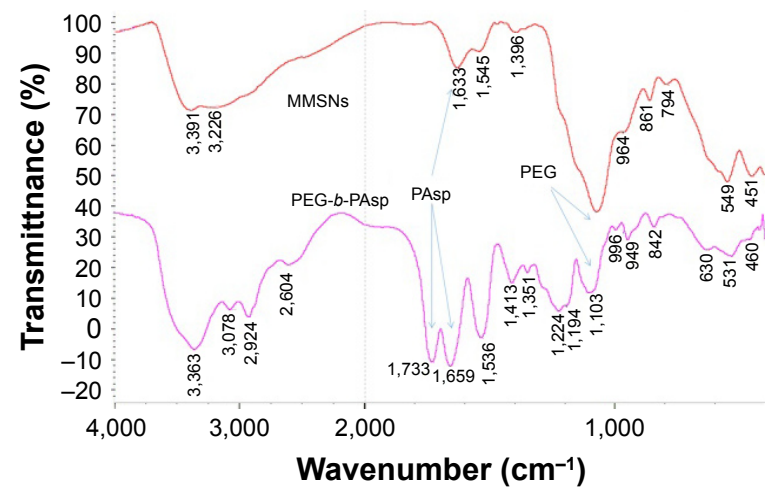

C

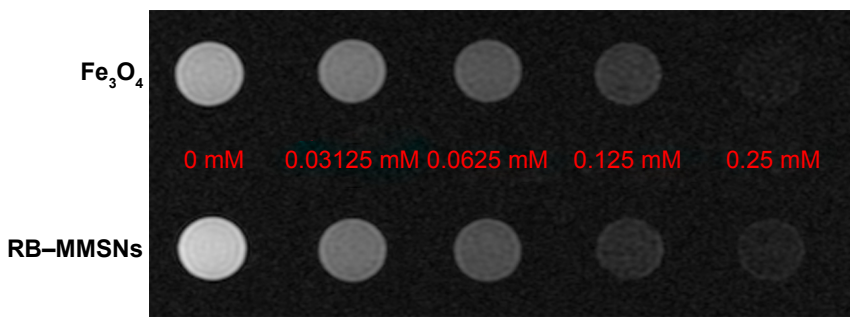

B

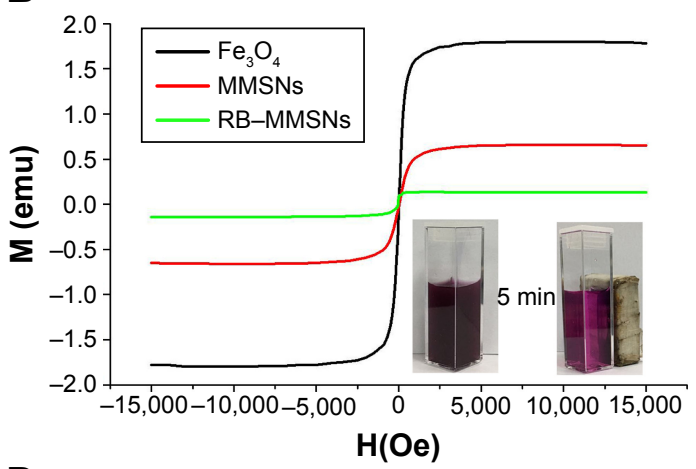

D

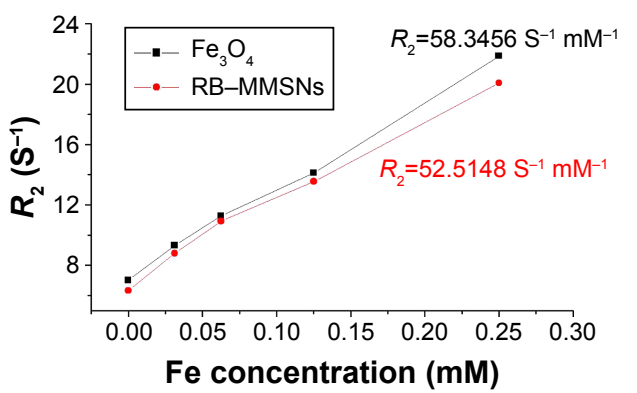

Figure 4 Characterization on the magnetic properties of nanoparticles.

Notes: (A) FTIR spectra of MMSNs and PEG-b-PAsp. (B) Hysteresis loop of Fe $\mathrm{O}_{4}$, MMSNs and RB-MMSNs normalized to per gram of the dry powder by the means of VSM. Inset: digital photos of RB-MMSNs aqueous solution without (left) and with (right) an external magnetic field. (C and $\mathbf{D}) \mathrm{T}_{2}$-weighted MRI (left) and $\mathrm{T}_{2}$ relaxation rates (right) of $\mathrm{Fe}_{3} \mathrm{O}_{4}$ or RB-MMSNs gel solutions at different Fe concentrations.

Abbreviations: FTIR, Fourier transform infrared spectroscopy; MMSNs, polyethylene glycol-b-polyaspartate-modified magnetic mesoporous silica; PEG-b-PAsp, polyethylene glycol-b-poly(aspartic acid); RB-MMSNs, polyethylene glycol-b-polyaspartate-modified rose bengal-loaded magnetic mesoporous silica; VSM, vibrating sample magnetometer; MRI, magnetic resonance image.
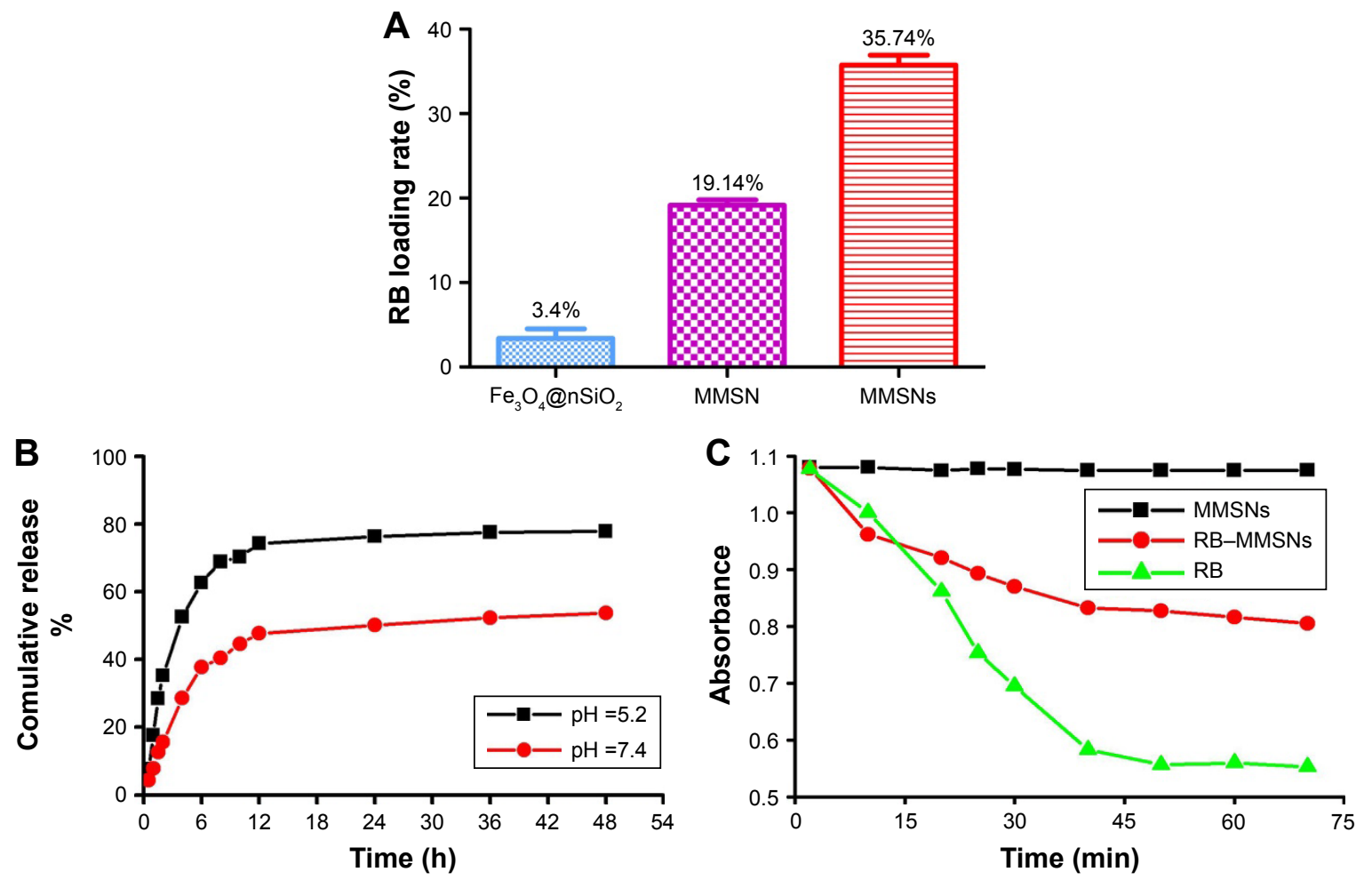

Figure 5 RB loading and release performance of nanoparticles.

Notes: (A) The columnar contrast diagram of $\mathrm{Fe}_{3} \mathrm{O}_{4} @ \mathrm{nSiO}_{2}, \mathrm{MMSN}$ and $\mathrm{MMSNs}$ in terms of RB loading rate. (B) $\mathrm{pH}$ responsiveness release curve of drugs in vitro. (C) Decay curves of the UA absorption band at $292 \mathrm{~nm}$ as a function of the irradiation time in the presence of MMSNs, RB-MMSNs and free RB.

Abbreviations: MMSN, magnetic mesoporous silica nanoparticle; MMSNs, polyethylene glycol-b-polyaspartate-modified magnetic mesoporous silica; RB, rose bengal; UA, uric acid; RB-MMSNs, polyethylene glycol-b-polyaspartate-modified rose bengal-loaded magnetic mesoporous silica. 
condition of $\mathrm{pH}$ 7.4. In neutral conditions, PAsp segments were hydrophobic and laid tightly on the surface of mesoporous silica, which locked RB in the pores and prevented the leakage of RB. Contrarily, in acidic conditions, the PAsp segments became hydrophilic and loose, exposing mesopores to the cytoplasm ( $\mathrm{pH}$ 5.1-5.4); hence, $\mathrm{RB}$ was rapidly released. Grafting amphiphilic block copolymer PEG-b-PAsp on the mesoporous surface successfully endowed the composite with $\mathrm{pH}$ responsiveness.

Singlet oxygen $\left({ }^{1} \mathrm{O}_{2}\right)$ is a critical factor in PDT, and its yield determines the effectiveness of PDT. ${ }^{37-40}$ When the RB is excited by the laser source, the laser energy is transferred to the triplet state through the energy-level change. Thus, efficient energy is transferred to the surrounding oxygen molecule to form ${ }^{1} \mathrm{O}_{2}$. We detected the ${ }^{1} \mathrm{O}_{2}$ produced by $\mathrm{RB}$ using the redox reaction between uric acid (UA) and ${ }^{1} \mathrm{O}_{2}$ mainly (Figure 5C). ${ }^{26}$ The absorption peak of UA at $296 \mathrm{~nm}$ reflected that the ${ }^{1} \mathrm{O}_{2}$ was generated from $\mathrm{RB}$. The time for the decrease of the UA absorption is inversely proportional to its reaction rate with ${ }^{1} \mathrm{O}_{2}$. For quantitative analysis, the ${ }^{1} \mathrm{O}_{2}$ level $\left(\eta_{(R B-M M S N S)}\right)$ was calculated as the following equation: ${ }^{26}$

$$
\eta_{(R B-M M S N S)}=\phi_{R B}^{1} \mathrm{O}_{2} \frac{\mathrm{t}_{R B}}{\mathrm{t}_{(R B-M M S N S)}}
$$

$\phi_{R B}{ }^{1} \mathrm{O}_{2}=0.75, \mathrm{t}_{R B}$ is the time for the decrease of UA in the presence of RB in an aqueous solution at the wavelength of $296 \mathrm{~nm}$ and $\mathrm{t}_{(R B-M M S N)}$ is the time for the decrease in the presence of RB-MMSNs. Finally, the ${ }^{1} \mathrm{O}_{2}$ level of RB-MMSNs was $\sim 0.45$, which guaranteed the ${ }^{1} \mathrm{O}_{2}$ yield for PDT.

\section{Cellular uptake and magnetic targeting in vitro}

Cellular uptake is essential for materials of drug carriers in vivo. Hence, cellular uptakes of free RB and RB-MMSNs were observed under a fluorescence microscope (Figure 6A). Endocytosis of RB-MMSNs by B16 cells was much more
A

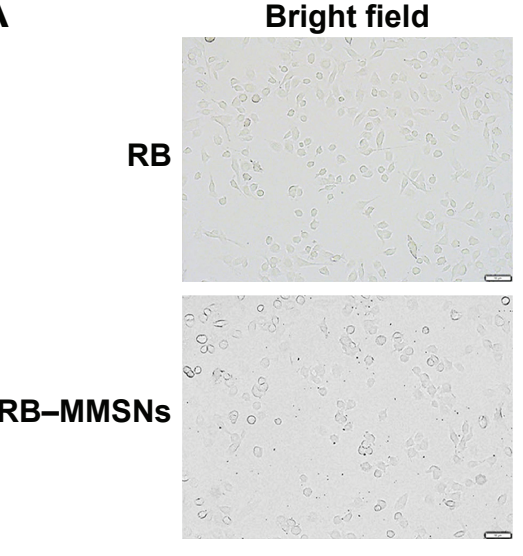

B

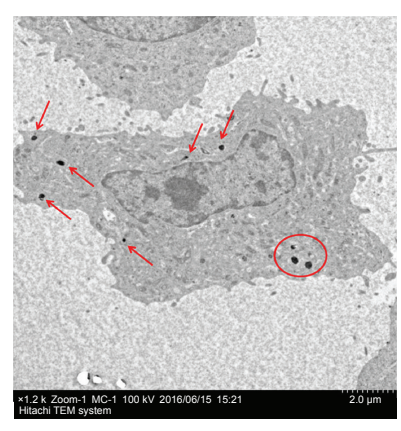

DAPI
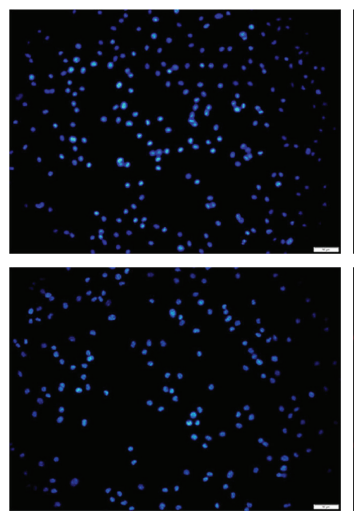

RB
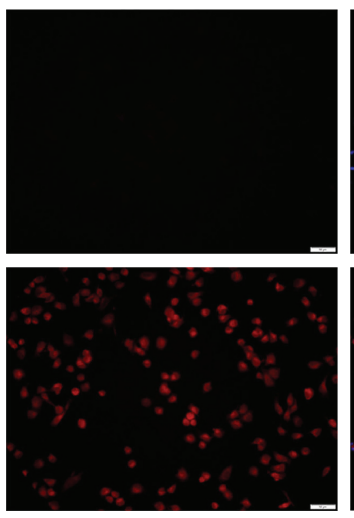

Overlay
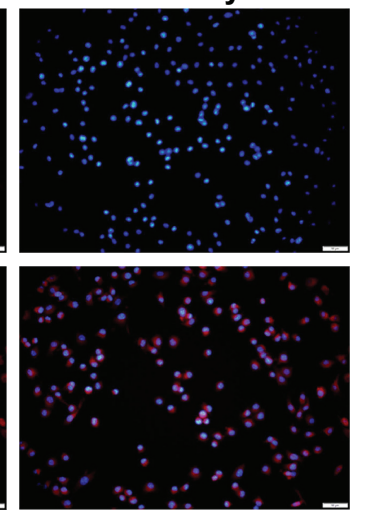

C

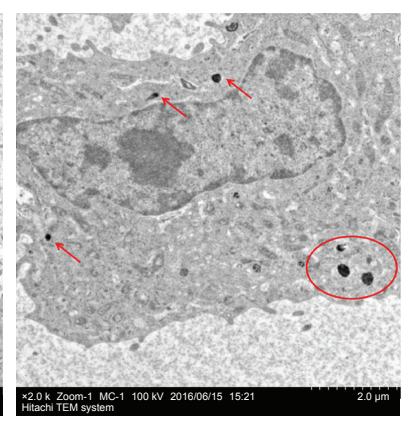

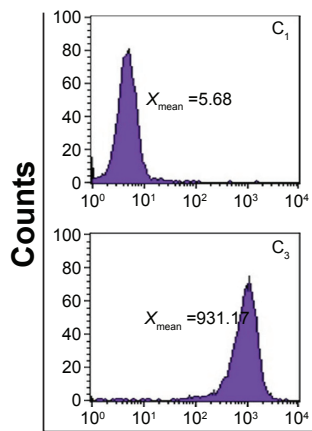
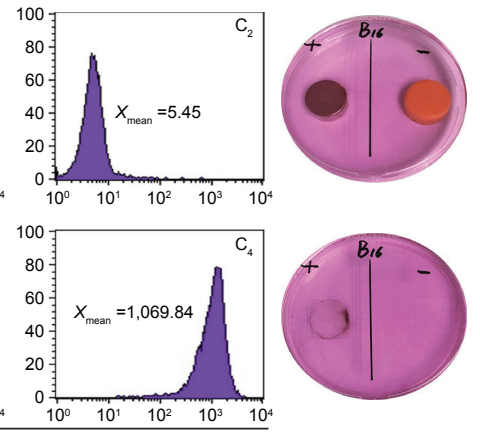

\section{Intensity}

Figure 6 Cellular uptake and magnetic targeting of RB-MMSNs in vitro.

Notes: (A) Fluorescence images of B 16 cells after co-incubation with $10 \mu \mathrm{g} / \mathrm{mL}$ RB and RB-MMSNs for $2 \mathrm{~h}$. Scale bar $=50 \mu \mathrm{m}$. (B) Low magnification (left) and high magnification (right) biological TEM images of BI6 cells treated with MMSNs using the concentration of $50 \mu \mathrm{g} / \mathrm{mL}$ for 2 h. Arrows and circles point out the intercellular locations for nanoparticles. (C) Flow cytometry showing the fluorescence intensity of Bl6 cells under different culture conditions for $2 \mathrm{~h}$ (left) and photos of BI6 cells culture dish (right). Abbreviations: RB, rose bengal; RB-MMSNs, polyethylene glycol-b-polyaspartate-modified rose bengal-loaded magnetic mesoporous silica; TEM, transmission electron microscope; MMSNs, polyethylene glycol-b-polyaspartate-modified magnetic mesoporous silica; DAPI, 4',6-diamidinio-2-phenylindole. 
evident than free $\mathrm{RB}$ as the free $\mathrm{RB}$ group demonstrated little red autofluorescence (as well as the blank cell control group, which is not shown in Figure 6A). Meanwhile, it was confirmed that RB-MMSNs were well endocytosed by B16 cells using a TEM (Figure 6B). Therefore, the results indicated that cellular uptake of RB was greatly enhanced through complexing RB with MMSNs, which was probably owing to the enhanced endocytosis by PEG- $b$-PAsp modification on MMSNs. ${ }^{41}$ In addition, the results hinted that MMSNs might improve the PDT. To testify the hypothesis, magnetic targeting experiments on PDT of RB-MMSNs in vitro were conducted (Figure 6C). After $2 \mathrm{~h}$ exposure to the magnetic field, fluorescent intensity of RB-MMSNs group $\left(X_{\text {mean }}=1,069.84\right)$ was much higher than that of the RB-MMSNs group without magnetic field $\left(X_{\text {mean }}=931.17\right)$ and the control group $\left(X_{\text {mean }}=5.68\right.$, $5.45)$, indicating the MMSNs with a distinct magnetic targeting effect could be used for magnetic field-controlled PDT in vitro. Besides, because of the cellular uptake during the RB-MMSNs' migration to the magnetic site, cells without exposing to the magnetic field demonstrated fluorescence, and additional cellular uptake rate occurred when blending the culture medium every 15 min to avoid aggradation of RB-MMSNs on the bottom of the culture dish.

\section{Cytotoxicity, PDT and detection of cellular ROS}

Besides, effective cellular uptakes, biocompatibility is also important for a drug carrier. Hence, cytotoxicity of MMSNs on three kinds of cells (Hela, B16 and L929) was tested with the CCK-8 method (Figure S2) at 24 and $48 \mathrm{~h}$. The results showed that all cell relative viability was almost $100 \%$ in all groups, even though MMSNs were at a high concentration of $200 \mu \mathrm{g} / \mathrm{mL}$, which indicated that MMSNs were biocompatible. PDT therapeutic effect was evaluated with CCK-8 kit and flow cytometry. Experimental results of half maximal inhibitory concentration $\left(\mathrm{IC}_{50}\right)$ fitted curve were based on CCK-8 method of RB-MMSNs. Without exposure to $535 \mathrm{~nm}$ green light (Figure 7A), free RB and RB-MMSNs at different concentrations showed low toxicity in darkness. After exposing to $535 \mathrm{~nm}$ green light $\left(25 \mathrm{~mW} / \mathrm{cm}^{2}\right.$ or $\left.4.5 \mathrm{~J} / \mathrm{cm}^{2}\right)$, cytotoxicity of RB-MMSNs at different concentrations was higher than free $\mathrm{RB}$, especially at the low concentration of $3.125-12.5 \mu \mathrm{g} / \mathrm{mL}$, demonstrating superiority of RB-MMSNs in PDT. Correspondingly, half inhibitory concentrations of RB-MMSNs and free RB were $4.85 \mu \mathrm{g} / \mathrm{mL}$ and $48.86 \mu \mathrm{g} / \mathrm{mL}$, respectively, according to the $\mathrm{IC}_{50}$ fitted curve. That is, $\mathrm{IC}_{50}$ of free $\mathrm{RB}$ was $\sim 10$ times of the $\mathrm{IC}_{50}$ of $\mathrm{RB}-\mathrm{MMSN}$. This significantly contributed to the extraordinary uptaking capacity of RB mediated by MMSNs and high RB loading rate. The apoptosis experiment proved that RB-mediated PDT did induce the dead B16 cells in proportion to the concentration of RB-MMSNs (shown in Figure 7B). Additionally, count of dead cells deduced by RB-MMSNs were $\sim 10$ times of that by free RB at the same concentration of $3.125 \mu \mathrm{g} / \mathrm{mL}$, implying that RB-MMSNs could greatly increase the cell death of RB. Corresponding to the CCK-8 result, MMSNs could greatly increase the endocytosis of RB and the efficiency of RB-based PDT by its $\mathrm{pH}$-responsive mechanism. Meanwhile, greatly increased endocytosis obviously decreased the phototoxicity of RB because of its much lower effective RB concentration applied in this strategy.

Mechanism of induced cell death during the PDT was further investigated by measuring the intracellular ROS level (Figure 7C). Non-fluorescent probe DCFH-DA was delivered into B16 cells before the ROS measurement. DCFH-DA could freely penetrate plasma lemma into the cytoplasm where DCFH-DA was hydrolyzed into dichlorofluorescin (DCFH). By reacting with intracellular ROS, DCFH was converted into fluorescent matter $7^{\prime}$-dichlorofluorescin (DCF), which could be used to measure the amount of ROS. After exposing to $535 \mathrm{~nm}$ green light, intracellular ROS in B16 cells incubated with free RB and RB-MMSNs was much higher than that without irradiation. Especially, the yield of intracellular ROS in B16 cells incubated with RB-MMSNs was remarkably higher than that with MMSNs, which was probably the normal level of intracellular ROS $(P<0.05)$. Notably, the intracellular ROS level of B16 cells incubated with RB and RB-MMSNs at high concentrations (25 $\mu \mathrm{g}$ / $\mathrm{mL}, 50 \mu \mathrm{g} / \mathrm{mL}$ ) were subtle different around the normal ROS level in the MMSNs group, which was due to the high concentration of RB and RB-MMSNs, which might destruct cell integrity, and the fluorescence intensity of DCF was deceased by a release of DCFH extracellularly. ${ }^{42}$

\section{Magnetic targeting and antitumor experiments in vivo}

Magnetic targeting of RB-MMSNs in vivo was investigated by small animal MRI (Figure $8 \mathrm{~A}$ ). The $\mathrm{T}_{2}$-weighted MRI image of post-injected mice within magnetic field and without magnetic field for $2 \mathrm{~h}$ differed. The $\mathrm{T}_{2}$-weighted MRI image of mice within the magnetic field was much darker, which indicated concentration of RB-MMSNs were increased in the magnetic field, implying the high efficiency of magnetic targeting to the tumor site. Afterward, mice were sacrificed to study the distribution of RB-MMSNs in different major 

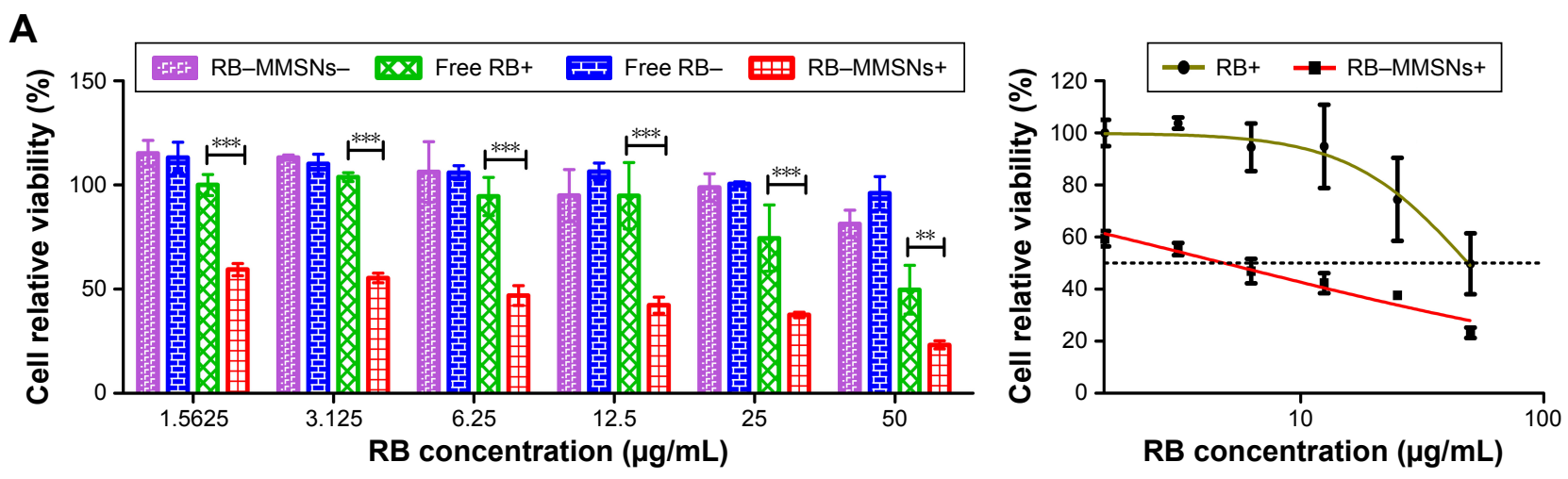

B
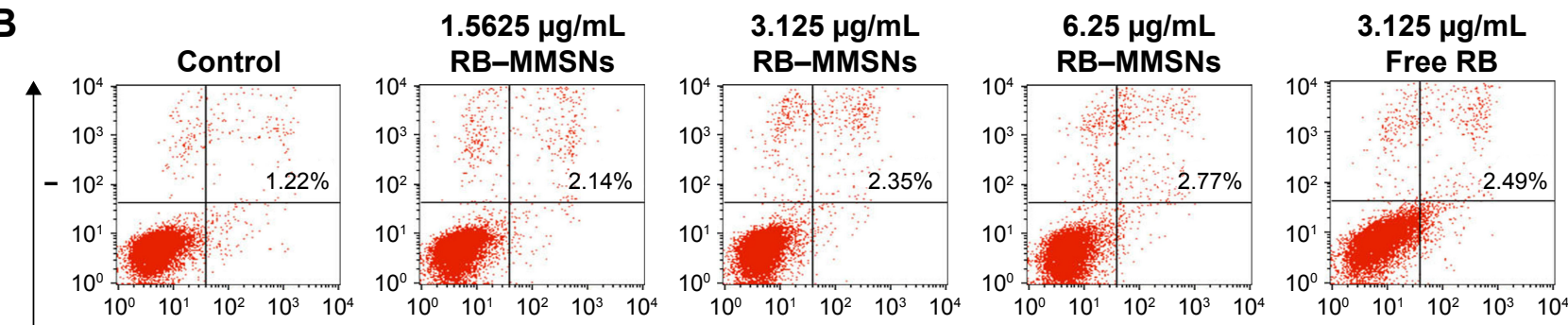

$\bar{\alpha}$
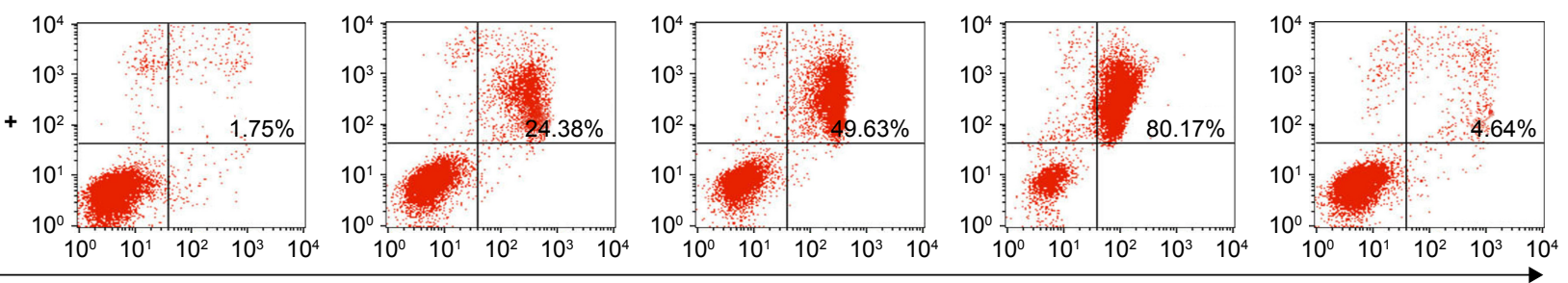

FITC-annexin v

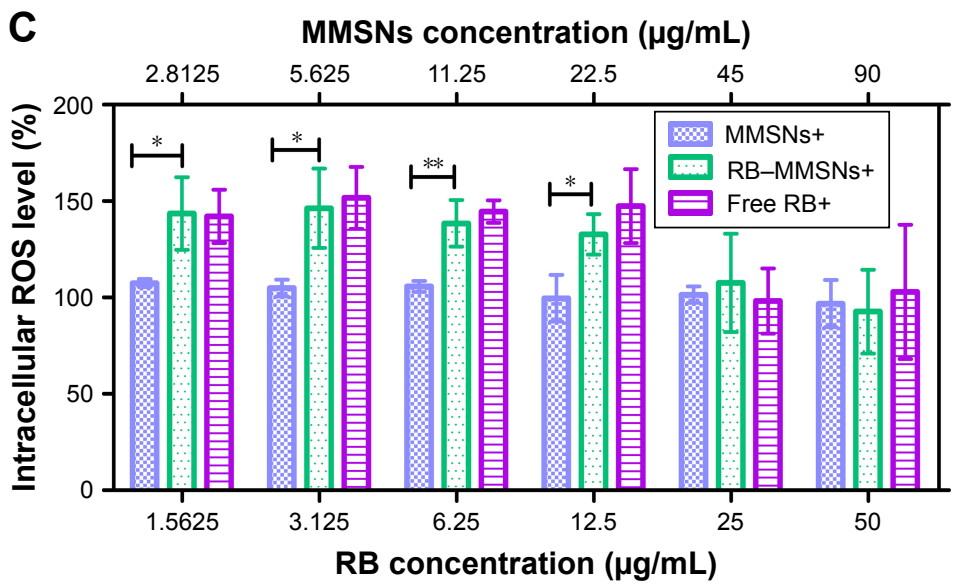

Figure 7 The therapeutical effect of the RB-MMSNs in vitro.

Notes: (A) Relative viabilities (left) and half inhibition curve (right) of BI6 cells treated with various concentrations of MMSNs, RB-MMSNs and RB with or without green light irradiation. The wavelength was $535 \mathrm{~nm}$, and the optical dose was $25 \mathrm{~mW} / \mathrm{cm}^{2}$ for 3 min (mean $\pm \mathrm{SD}, \mathrm{n}=3$; $* * P<0.0 \mathrm{I}$, $* * * P<0.00 \mathrm{I}$.) (B) Flow cytometry showing the apoptosis of BI6 cells treated with different concentrations of free RB and RB-MMSNs without (up) or with (down) $535 \mathrm{~nm}$ green light irradiation for $3 \mathrm{~min}\left(25 \mathrm{~mW} / \mathrm{cm}^{2}\right.$ ). (C) ROS generation of $\mathrm{BI} 6$ cells incubated with MMSNs, RB-MMSNs and free RB with green light irradiation (mean $\pm S D, n=3$; $* P<0.05$, $* * P<0.01$ ). The wavelength was $535 \mathrm{~nm}$, and the optical dose was $25 \mathrm{~mW} / \mathrm{cm}^{2}$ for $3 \mathrm{~min}$.

Abbreviations: FITC, fluorescein isothiocyanate; MMSNs, polyethylene glycol-b-polyaspartate-modified magnetic mesoporous silica; PI, propidium iodide; RB-MMSNs, polyethylene glycol-b-polyaspartate-modified rose bengal-loaded magnetic mesoporous silica; RB, rose bengal; ROS, reactive oxygen species.

organs stained with Prussian blue (Figure 8B). RB-MMSNs within the magnetic field were much more detained in the tumor site than those without the magnetic field. A falsepositive result occurred in heart because of rich blood in heart stained by Prussian blue easily. Meanwhile, other main organs treated with RB-MMSNs were stained by hematoxylin and eosin (H\&E) and showed no toxic and side effects of RB-MMSNs in healthy mice (Figure S3). 
A

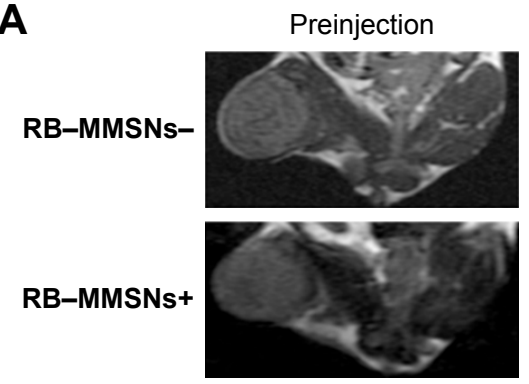

B

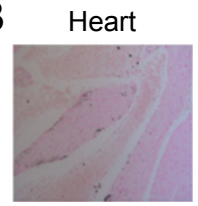

Liver

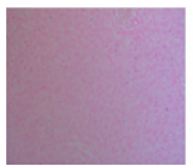

Postinjection
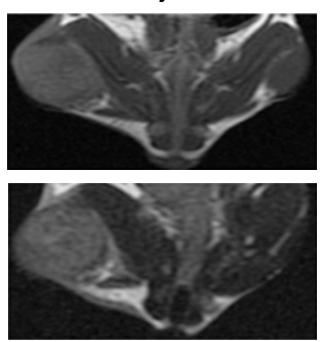

Lung
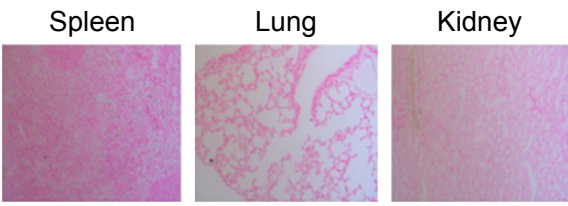

Postinjection at $2 \mathrm{~h}$
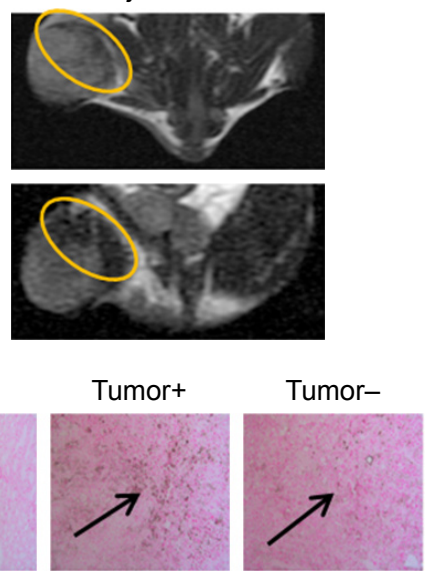

Figure 8 Magnetic targeting of RB-MMSNs in vivo.

Notes: (A) $\mathrm{T}_{2}$-weighted MRI of mice: preinjection, injection and $2 \mathrm{~h}$ postinjection with RB-MMSNs. Circles point out the locations of nanocomposites in tumor site. (B) Prussian blue-stained images of major organs and tumor tissues (black arrows indicate RB-MMSNs deposition). Scale bar $=50 \mu \mathrm{m}$.

Abbreviations: MRI, magnetic resonance image; RB-MMSNs, polyethylene glycol-b-polyaspartate-modified rose bengal-loaded magnetic mesoporous silica.

The therapeutically effect of RB-MMSNs-mediated PDT was investigated by measuring survival period, tumor volume and body weight of C57BL/6J mice inoculated with B16 cells in right hindlegs in four groups (control, RB+, RB-MMSNs+ and M+RB-MMSNs+). In the fourth day after inoculation, mice in each group were treated with the condition formerly arranged correspondingly every 2 days for five times. Compared with the control group, the survival period of mice within the magnetic field was significant prolonged
$(P<0.05$; Figure 9A). Moreover, after treatments for four times (day 10), tumor volumes of treatment groups became much smaller than those of the control group, indicating inhibition to the tumors in statistical difference $(P<0.05)$. Additionally, during the treatment period (Figure 9B), volumes of RB-MMSNs-treated tumor within the magnetic field proliferated were the smallest, while the volumes of RB and MMSNs showed no obvious difference. In the 14 th day, the end of the treatment period, the volumes of
A

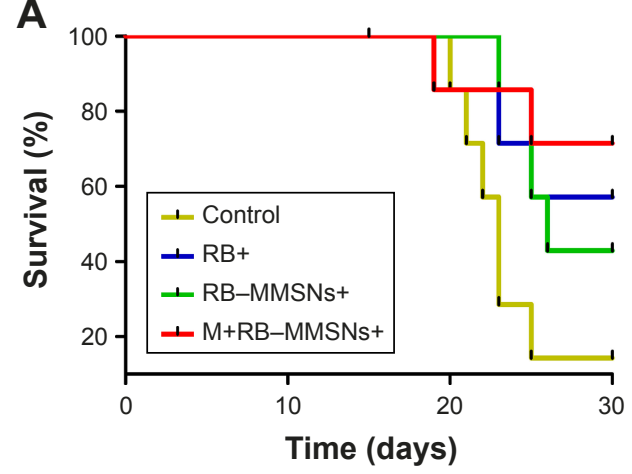

C
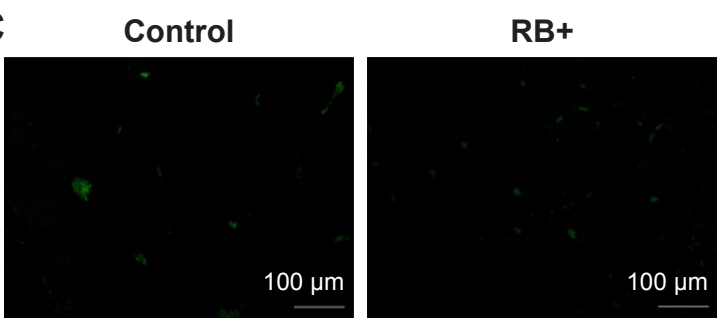
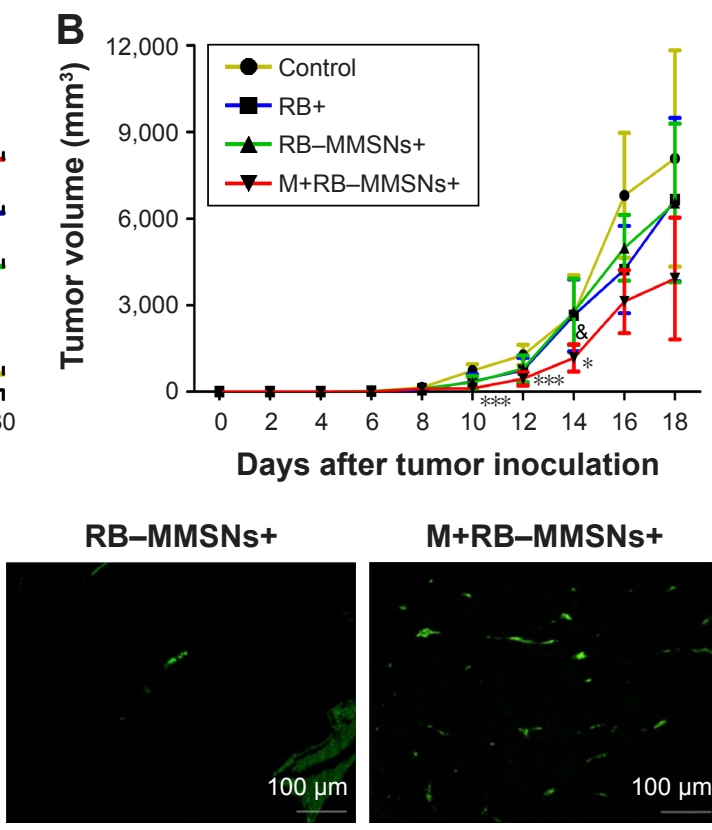

M+RB-MMSNs+

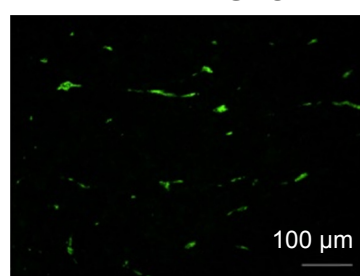

Figure 9 Antitumor experiments in vivo.

Notes: (A and B) The survival, tumor growth and body weight change curves of different treatment groups (control, RB+, RB-MMSNs+ and M+RB-MMSNs+). (C) TUNEL analysis of tumor sections from the C57BL/6] xenografts mice treated with different therapeutics (control, RB+, RB-MMSNs+ and M+RB-MMSNs+). *Indicates $P<0.05$, $* * * P<0.00$ I, they are all the statistically significant differences between the control group and the treatment group of M+RB-MMSNs+. ${ }^{\&}$ Indicates the treatment group of M+RB-MMSNs+ shows significant differences with the other three groups (control, RB+ and RB-MMSNs+) at day 14.

Abbreviations: RB, rose bengal; RB-MMSNs, polyethylene glycol-b-polyaspartate-modified rose bengal-loaded magnetic mesoporous silica; TUNEL, terminal deoxynucleotidyl transferase dUTP nick-end labeling. 
RB-MMSNs-treated tumor within the magnetic field were significantly smaller than those of other groups. Meanwhile, no significant difference in mice weights was demonstrated in low phototoxicity of PDT (Figure S4). Antitumor effect was further analyzed by staining of TUNEL apoptosis cells of main organs of RB-MMSNs-treated mice to green (Figure 9C), and the result showed that no apoptosis occurred in the control group. Slight apoptosis happened in the free $\mathrm{RB}+$ and RB-MMSNs+ groups without the magnetic field. Large-scale apoptosis in the M+RB-MMSNs+ group indicated the superiority of MMSNs as a promising drug carrier. All these results demonstrated that magnetic targeting and $\mathrm{pH}$ responsibility of the nanocomposite could greatly enhance the PDT efficacy by increasing the enrichment and endocytosis of RB in the tumor site within the magnetic field and enhancing the cellular release, probably responding to the $\mathrm{pH}$ change from extracellular environment to the endosome.

\section{Conclusion}

A novel magnetic targeting and polyethylene glycol- $b$-poly aspartic acid (PEG- $b$-PAsp)-mediated $\mathrm{pH}$-responsive superparamagnetic $\mathrm{Fe}_{3} \mathrm{O}_{4}$ mesoporous silica was well developed as a drug-delivery carrier for photosensitizer RB. The composites (RB-MMSNs) could greatly enhance the cellular uptake and induce apoptosis in a quite low concentration. They also could significantly inhibit tumor growth by irradiating tumorbearing mice under $535 \mathrm{~nm}$ green light in the magnetic field. $\mathrm{RB}$ was caged into the mesoporous pores by the hydrophobic layer of Asp segments in the neutral solution. After endocytosis, PAsp segments converted into hydrophilic, responding to the $\mathrm{pH}$ of endosomes, and $\mathrm{RB}$ was rapidly released from unlocked mesoporous pores into the cytoplasm. Henceforth, MMSNs effectively increased the therapeutical concentration of hydrophobic photosensitizer RB in the tumor site and decreased the leakage of photosensitizer during the delivery. RB-MMSNs as a magnetic targeting and $\mathrm{pH}$-responsive composite may indeed have great potential in clinical cancer photodynamic treatment.

\section{Acknowledgments}

This work was financially supported by a grant from the National Natural Science Foundation of China (81603124), Shanghai Natural Science Foundation (16ZR1444200) and Shanghai Municipal Planning Commission of Science and Research Fund for Youth Project (20164Y0039).

\section{Disclosure}

The authors report no conflicts of interest in this work.

\section{References}

1. Monge-Fuentes V, Muehlmann LA, de Azevedo RB. Perspectives on the application of nanotechnology in photodynamic therapy for the treatment of melanoma. Nano Rev. 2014;5.

2. Zhao B, Yin JJ, Bilski PJ, Chignell CF, Roberts JE, He YY. Enhanced photodynamic efficacy towards melanoma cells by encapsulation of Pc4 in silica nanoparticles. Toxicol Appl Pharmacol. 2009;241(2):163-172.

3. Fan W, Huang P, Chen X. Overcoming the Achilles' heel of photodynamic therapy. Chem Soc Rev. 2016;45(23):6488-6519.

4. Inada NM, Kurachi C, Ferreira J, et al. Treatment of vulvar/vaginal condyloma by HPV: developed instrumentation and clinical report. Proc SPIE. Photodynamic Therapy: Back to the Future; 2009;738054.

5. Atchison J, Kamila S, McEwan C, et al. Modulation of ROS production in photodynamic therapy using a $\mathrm{pH}$ controlled photoinduced electron transfer (PET) based sensitiser. Chem Commun (Camb). 2015;51(94): 16832-16835.

6. Heukers R, van Bergen EHP, Oliveira S. Nanobody-photosensitizer conjugates for targeted photodynamic therapy. Nanomedicine. 2014; 10(7):1441-1451.

7. Master A, Livingston M, Sen GA. Photodynamic nanomedicine in the treatment of solid tumors: perspectives and challenges. $J$ Control Release. 2013;168(1):88-102.

8. Zhao H, Yin R, Chen D, et al. In vitro and in vivo antitumor activity of a novel hypocrellin B derivative for photodynamic therapy. Photodiagnosis Photodyn Ther. 2014;11(2):204-212.

9. Yin H, Ye X, Niu Q, Wang C, Li Y. Time course of apoptosis induced by photodynamic therapy with PsD007 in LT12 acute myeloid leukemia cells. Lasers Med Sci. 2016;31(5):817-824.

10. Xue J, Li C, Liu H, Wei J, Chen N, Huang J. Optimal light dose and drug dosage in the photodynamic treatment using PHOTOCYANINE. Photodiagnosis Photodyn Ther. 2011;8(3):267-274.

11. Li Z, Wang C, Cheng L, et al. PEG-functionalized iron oxide nanoclusters loaded with chlorin e6 for targeted, NIR light induced, photodynamic therapy. Biomaterials. 2013;34(36):9160-9170.

12. Lin A, Hahn SM. Photodynamic therapy: a light in the darkness? Clin Cancer Res. 2009;15(13):4252-4253.

13. Delrosso G, Bornacina C, Farinelli P, Bellinzona F, Leigheb G, Colombo E. Bath PUVA and psoriasis: is a milder treatment a worse treatment? Dermatology. 2008;216(3):191-193.

14. Li J, Tripathi RC, Tripathi BJ. Drug-induced ocular disorders. Drug Saf. 2008;31(2):127-141.

15. Navarro JR, Lerouge F, Cepraga C, et al. Nanocarriers with ultrahigh chromophore loading for fluorescence bio-imaging and photodynamic therapy. Biomaterials. 2013;34(33):8344-8351.

16. Saji H, Song W, Furumoto K, Kato H, Engleman EG. Systemic antitumor effect of intratumoral injection of dendritic cells in combination with local photodynamic therapy. Clin Cancer Res. 2006;12(8):2568-2574.

17. Zheng H, Wen S, Zhang Y, Sun Z. Organosilane and polyethylene glycol functionalized magnetic mesoporous silica nanoparticles as carriers for $\mathrm{CpG}$ immunotherapy in vitro and in vivo. PLoS One. 2015; 10(10):e140265.

18. Zhang Y, Shen Y, Teng X, Yan M, Bi H, Morais PC. Mitochondriatargeting nanoplatform with fluorescent carbon dots for long time imaging and magnetic field-enhanced cellular uptake. ACS Appl Mater Interfaces. 2015;7(19):10201-10212.

19. Yi C, Liu L, Li CW, Zhang J, Yang M. Synthesis, characterization and biomedical application of multifunctional luminomagnetic core-shell nanoparticles. Mater Sci Eng C Mater Biol Appl. 2015;46:32-40.

20. Tarn D, Ashley CE, Xue M, Carnes EC, Zink JI, Brinker CJ. Mesoporous silica nanoparticle nanocarriers: biofunctionality and biocompatibility. Acc Chem Res. 2013;46(3):792-801.

21. Liu ZT, Xiong L, Liu ZP, Miao XY, Lin LW, Wen Y. In vivo and in vitro evaluation of the cytotoxic effects of Photosan-loaded hollow silica nanoparticles on liver cancer. Nanoscale Res Lett. 2014;9(1):319.

22. Bose B, Dube A. Photodynamic efficacy of chlorin p6: a pH dependent study in aqueous and lipid environment. $J$ Photochem Photobiol B. 2008;93(1):32-35. 
23. Wang Y, Gu H. Core-shell-type magnetic mesoporous silica nanocomposites for bioimaging and therapeutic agent delivery. Adv Mater. 2015;27(3):576-585.

24. Tian F, Chen G, Yi P, et al. Fates of Fe3O4 and Fe3O4@SiO2 nanoparticles in human mesenchymal stem cells assessed by synchrotron radiation-based techniques. Biomaterials. 2014;35(24):6412-6421.

25. Ponta A, Bae Y. Tumor-preferential sustained drug release enhances antitumor activity of block copolymer micelles. J Drug Target. 2014; 22(7):619-628.

26. Gianotti E, Martins EB, Cucinotta F, et al. An efficient rose bengal based nanoplatform for photodynamic therapy. Chemistry. 2014;20(35): 10921-10925.

27. Wang S, Zhang H, Zhan J, Al E. Preparation of $\mathrm{pH} /$ magnetic dual responsive nanocomplex $\mathrm{Fe}_{3} \mathrm{O}_{4} @ \mathrm{SiO}_{2} @ \mathrm{PEG}-b$-PAsp@DOX and its cytotoxicity effect on A549 cells. Acad J Second Mil Med Univ. 2016; 03:288-294.

28. Lu Y, Yin Y, And BTM, Xia Y. Modifying the surface properties of superparamagnetic iron oxide nanoparticles through a sol? Gel approach. Nano Lett. 2002;2(3):183-186.

29. Deng Y, Qi D, Deng C, Zhang X, Zhao D. Superparamagnetic highmagnetization microspheres with an Fe3O4@SiO2 core and perpendicularly aligned mesoporous $\mathrm{SiO} 2$ shell for removal of microcystins. J Am Chem Soc. 2008;130(1):28-29.

30. Ma X, Qu Q, Zhao Y. Targeted delivery of 5-aminolevulinic acid by multifunctional hollow mesoporous silica nanoparticles for photodynamic skin cancer therapy. ACS Appl Mater Interfaces. 2015;7(20): 10671-10676.

31. Abbasi AN, Pirayesh IJ, Hatamian M, Arabfirouzjaei M, Javadpour J, Rashidi MR. Doxorubicin loaded large-pore mesoporous hydroxyapatite coated superparamagnetic $\mathrm{Fe} 3 \mathrm{O} 4$ nanoparticles for cancer treatment. Int J Pharm. 2016;509(1-2):159-167.

32. Scott D, Rohr J, Bae Y. Nanoparticulate formulations of mithramycin analogs for enhanced cytotoxicity. Int J Nanomedicine. 2011;6: 2757-2767.
33. Howard MD, Ponta A, Eckman A, Jay M, Bae Y. Polymer micelles with hydrazone-ester dual linkers for tunable release of dexamethasone. Pharm Res. 2011;28(10):2435-2446.

34. Kim KS, Kim J, Lee JY, et al. Correction: stimuli-responsive magnetic nanoparticles for tumor-targeted bimodal imaging and photodynamic/ hyperthermia combination therapy. Nanoscale. 2016;8(25):12843.

35. Liang PC, Chen YC, Chiang CF, et al. Doxorubicin-modified magnetic nanoparticles as a drug delivery system for magnetic resonance imaging-monitoring magnet-enhancing tumor chemotherapy. Int $J$ Nanomedicine. 2016;11:2021-2037.

36. Mishra SK, Kumar BS, Khushu S, Tripathi RP, Gangenahalli G. Increased transverse relaxivity in ultrasmall superparamagnetic iron oxide nanoparticles used as MRI contrast agent for biomedical imaging. Contrast Media Mol Imaging. 2016;11(5):350-361.

37. Wang B, Wang JH, Liu Q, et al. Rose-bengal-conjugated gold nanorods for in vivo photodynamic and photothermal oral cancer therapies. Biomaterials. 2014;35(6):1954-1966.

38. Tang Y, Hu J, Elmenoufy AH, Yang X. Highly efficient FRET system capable of deep photodynamic therapy established on X-ray excited mesoporous LaF3:Tb scintillating nanoparticles. ACS Appl Mater Interfaces. 2015;7(22):12261-12269.

39. Pena LS, Marin GH, Aviles K, et al. Enhanced singlet oxygen production by photodynamic therapy and a novel method for its intracellular measurement. Cancer Biother Radiopharm. 2014;29(10):435-443.

40. Lu S, Tu D, Hu P, et al. Multifunctional nano-bioprobes based on rattlestructured upconverting luminescent nanoparticles. Angew Chem Int Ed Engl. 2015;54(27):7915-7919.

41. Tian B, Wang C, Zhang S, Feng L, Liu Z. Photothermally enhanced photodynamic therapy delivered by nano-graphene oxide. ACS Nano. 2011;5(9):7000-7009.

42. Chen MH, Hanagata N, Ikoma T, et al. Hafnium-doped hydroxyapatite nanoparticles with ionizing radiation for lung cancer treatment. Acta Biomater. 2016;37:165-173. 


\section{Supplementary materials Synthesis of $\mathrm{Fe}_{3} \mathrm{O}_{4}$ nanoparticles}

$\mathrm{Fe}_{3} \mathrm{O}_{4}$ nanoparticles were synthesized by solvothermal reaction; the synthesis procedure was as follows. First, $1.44 \mathrm{~g}$ $\mathrm{Na}_{3}$ Cit was dissolved in $180 \mathrm{~mL}$ EG; afterward, $3.3 \mathrm{~g}$ $\mathrm{FeCl}_{3} \cdot 6 \mathrm{H}_{2} \mathrm{O}$ and $7.26 \mathrm{~g} \mathrm{NaOAc}$ were successively added with vigorous stirring, and then, the mixture was sealed in a Teflon-lined autoclave (200 mL capacity) and heated at $200^{\circ} \mathrm{C}$ for $12 \mathrm{~h}$. After the autoclave was cooled down to room temperature, the black products were alternately washed with ethanol and deionized water for three times and separated by the NIB magnet purchased from Dongguan Fuqiang Magnetic Industry Co., Ltd.; the maximum magnetic energy product was $285 \mathrm{~kJ} / \mathrm{m}^{3}$, and the size was $3 \times 1.5 \times 1 \mathrm{~cm}$. Finally, the products were separated in $36 \mathrm{~mL}$ anhydrous ethanol and then kept in refrigerator at $4^{\circ} \mathrm{C}$ for further experiments.

\section{Synthesis of PEG-b-PAsp}

Synthesis of L-aspartate benzyl ester- $N$-carboxylic acid anhydride (BLA-NCA)

First, $4.8 \mathrm{~g}$ BLA was dispersed in $60 \mathrm{~mL}$ dried tetrahydrofuran (THF) in a flask under oil bath at $60^{\circ} \mathrm{C}$; then, $6 \mathrm{~g}$ triphosgene was quickly added into the flask. The flask was took out, and $\mathrm{N}_{2}$ was blew into the flask to remove phosgene and hydrogen chloride. The product was concentrated to be viscous liquid after rotary evaporation and then diluted by appropriate chloroform in a beaker. Approximately, $400 \mathrm{~mL}$ $n$-hexane was added into the beaker to precipitate the crude BLA-NCA at $4^{\circ} \mathrm{C}$ for $12 \mathrm{~h}$. The crude product was recrystallized by a mixture solvent ( $50 \%$ acetidin:50\% $n$-hexane). BLA-NCA was obtained after vacuum drying.

\section{Synthesis of polyethylene glycol-b-poly(aspartic acid} benzyl ester) (PEG-b-PBLA)

A total of $1 \mathrm{~g}$ PEG-NH $\mathrm{H}_{2}$ was dissolved in $40 \mathrm{~mL}$ dried $\mathrm{CH}_{2} \mathrm{Cl}_{2}$; afterward, $5 \mathrm{~g}$ BLA-NCA was added into the system. The mixture were kept stirring in an atmosphere of $\mathrm{N}_{2}$ at $32^{\circ} \mathrm{C}$ for $72 \mathrm{~h}$. Then concentrated PEG- $b$-PBLA was obtained by rotary evaporation and precipitated with diethyl ether at $4^{\circ} \mathrm{C}$ for $12 \mathrm{~h}$. After vacuum filtration and drying, PEG- $b$-PBLA was obtained as a white powder.

\section{Hydrolysis of PEG-b-PBLA}

A total of $4 \mathrm{~g}$ of PEG- $b$-PBLA was dissolved in a mixture solution (100 mL THF and $100 \mathrm{~mL} 1 \mathrm{M} \mathrm{NaOH})$ and magnetically stirred for $10 \mathrm{~h}$. Then, the concentrated mixture was dialyzed against a $0.1 \mathrm{~mol} / \mathrm{L} \mathrm{HCl}$ solution for $24 \mathrm{~h}$ and sequentially dialyzed against deionized water for $24 \mathrm{~h}$. After vacuum filtration and drying, PEG- $b$-PAsp was obtained as a white flocculent powder.

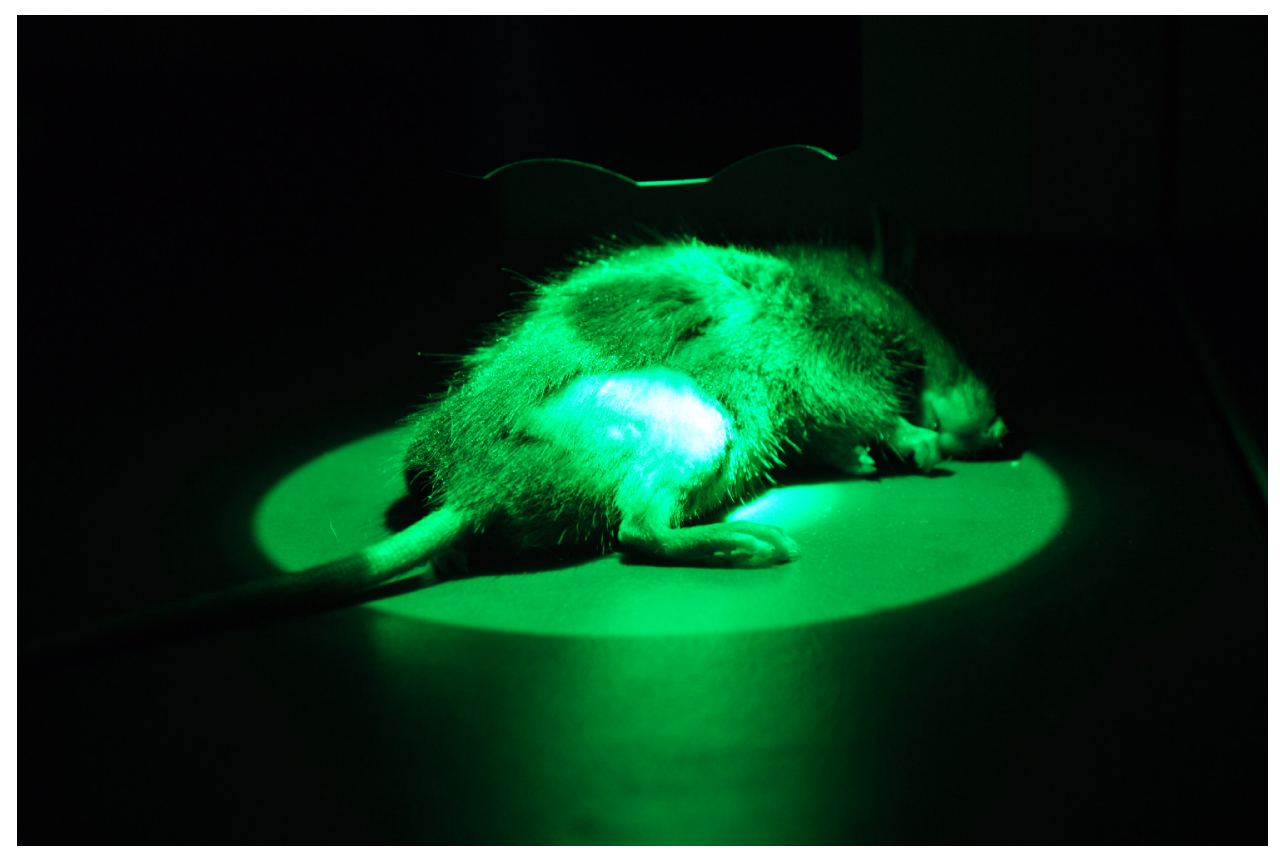

Figure SI Digital image of PDT application in vivo. 

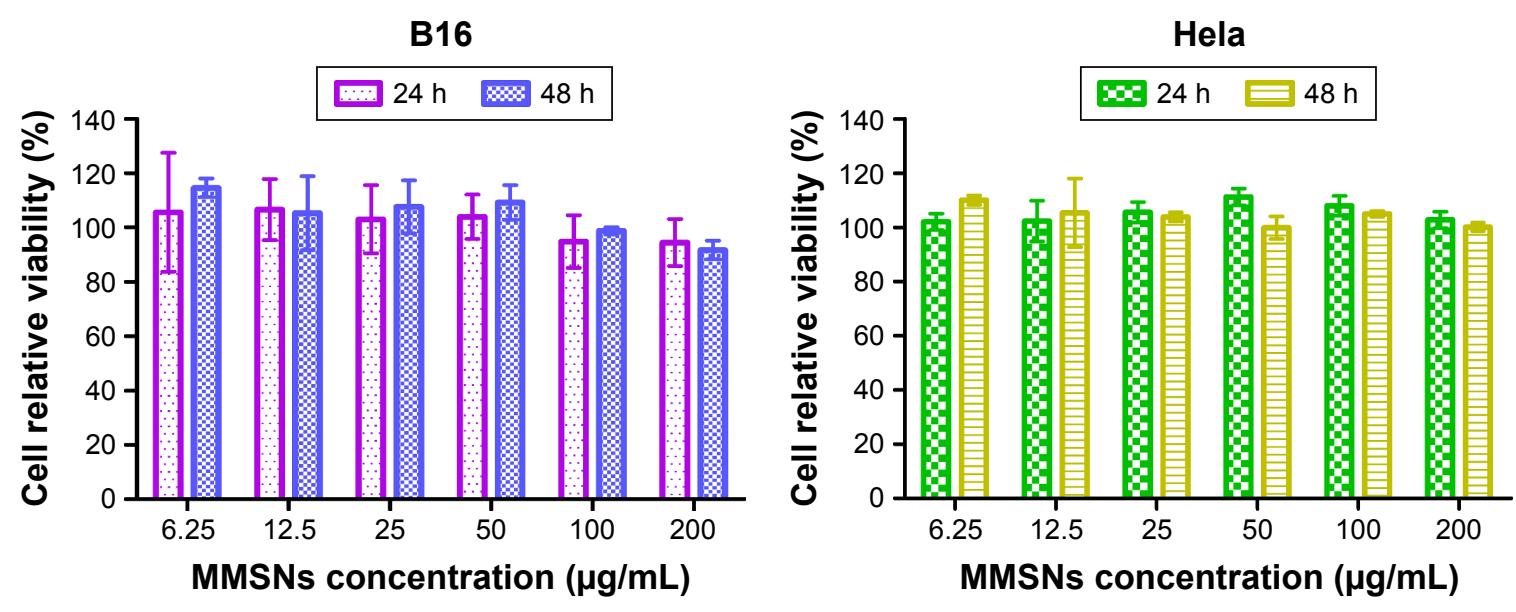

\section{L929}

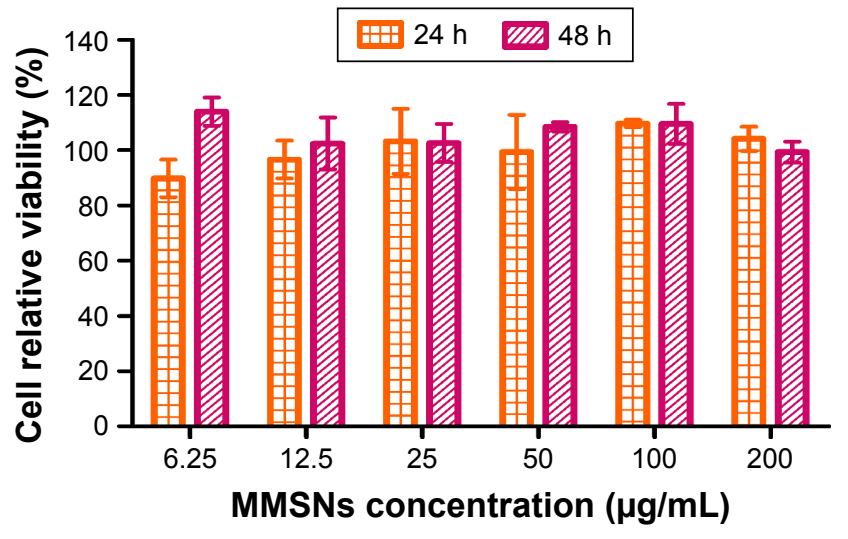

Figure S2 Relative viabilities of B16, Hela and L929 cells after being incubated with various concentrations of MMSNs for 24 and 48 h. Abbreviation: MMSNs, polyethylene glycol-b-polyaspartate-modified magnetic mesoporous silica.

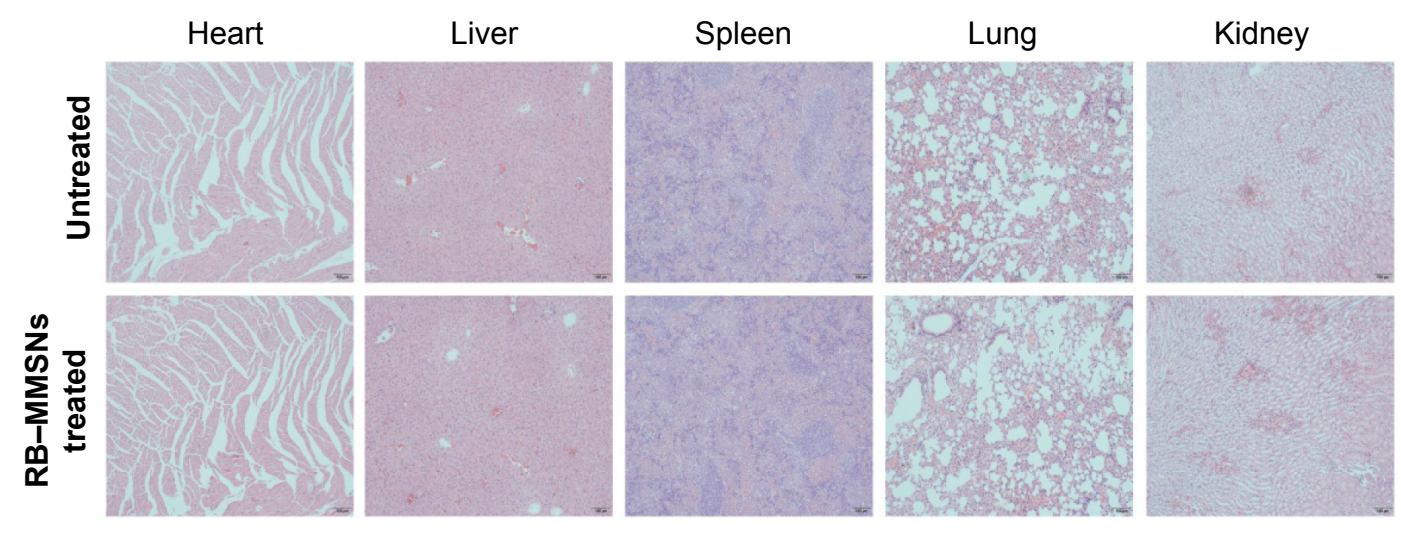

Figure S3 H\&E-stained images of major organs collected from healthy C57BL/6 J mice untreated and RB-MMSNs injected 20 days later. Scale bar $=100 \mu \mathrm{m}$. Abbreviations: H\&E, hematoxylin and eosin; RB-MMSNs, polyethylene glycol-b-polyaspartate-modified rose bengal-loaded magnetic mesoporous silica. 


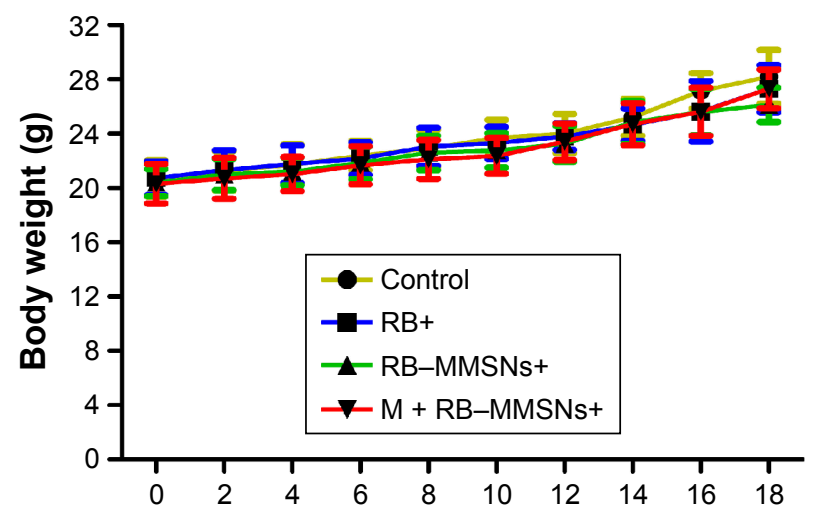

Days after tumor inoculation

Figure S4 Body weight change curves of different treatment groups (control, RB+, RB-MMSNs+ and M+RB-MMSNs+).

Abbreviations: RB, rose bengal; RB-MMSNs, polyethylene glycol-b-polyaspartate-modified rose bengal-loaded magnetic mesoporous silica.

\section{Publish your work in this journal}

The International Journal of Nanomedicine is an international, peerreviewed journal focusing on the application of nanotechnology in diagnostics, therapeutics, and drug delivery systems throughout the biomedical field. This journal is indexed on PubMed Central, MedLine, CAS, SciSearch $®$, Current Contents ${ }^{\circledR} /$ Clinical Medicine,
Journal Citation Reports/Science Edition, EMBase, Scopus and the Elsevier Bibliographic databases. The manuscript management system is completely online and includes a very quick and fair peer-review system, which is all easy to use. Visit http://www.dovepress.com/ testimonials.php to read real quotes from published authors.

Submit your manuscript here: http://www.dovepress.com/international-journal-of-nanomedicine-journal 